\title{
Changes in co-movement and risk transmission between South Asian stock markets amidst the development of regional co-operation
}

\author{
Muhammad Niaz Khan ${ }^{1}$. Suzanne G. M. Fifield ${ }^{2}$.. \\ Nongnuch Tantisantiwong ${ }^{3} \cdot$ David M. Power ${ }^{2}$
}

Accepted: 24 February 2021 / Published online: 7 April 2021

(C) The Author(s) 2021

\begin{abstract}
This paper documents evidence of changes in the co-movement of stock returns and risk transmission among four South Asian stock markets over periods of regional market reform and global market instability. The sample period (1993-2015) is disaggregated into three sub-periods: before and after the establishment of the South Asian Federation of Exchanges (SAFE) and after the 2008 Global Financial Crisis. The principal components investigation and cointegration analysis conclude that the co-movement among stock returns in this region altered amidst a change in the institutional context and global economic uncertainty. Using a tetra-variate GARCHBEKK model, we find that, after the establishment of SAFE, the interactions among the markets increased through volatility spillovers, but decreased through shock spillovers. In addition, there were more shock and volatility spillovers in the last sub-period as compared to the first two sub-periods, indicating that risk transmission across countries increased during the period of uncertainty. In particular, the Indian stock market was a risk spreader in South Asia after the setup of SAFE and its influence on the regional stock markets increased even further after the 2008 Global Financial Crisis.
\end{abstract}

Keywords Co-movement · Financial liberalisation $\cdot$ Risk transmission

JEL Classification C58 $\cdot \mathrm{G} 14 \cdot \mathrm{G} 15 \cdot \mathrm{G} 17$

Suzanne G. M. Fifield

s.g.m.fifield@dundee.ac.uk

1 University of Science and Technology Bannu, Bannu, Pakistan

2 University of Dundee School of Business, University of Dundee, Dundee DD1 4HN, Scotland, UK

3 Krungthai Bank, Bangkok, Thailand 


\section{Introduction}

Since 2000, the governments of various South Asian economies (including those of Bangladesh, India, Pakistan and Sri Lanka) have promoted regional trade and investment under the South Asian Association for Regional Cooperation (SAARC). Various regional financial and trade co-operation agreements have been introduced, such as the South Asian Federation of Exchanges (SAFE) and the South Asian Free Trade Agreement (SAFTA) (Banik et al. 2009; SAFE 2010). ${ }^{1}$ At the same time, the stock exchanges of Bangladesh, India, Pakistan and Sri Lanka were reformed. For example, the Security and Exchange Commission of Pakistan (SECP) implemented a $T+3$ settlement period, rationalised risk management measures and imposed circuit breakers (Hameed and Ashraf 2006). While these reforms were being implemented, the South Asian stock markets experienced relatively high growth rates. According to Standard and Poor's (2010), the markets in Bangladesh, India, Pakistan and Sri Lanka reported growth rates for market capitalisation in excess of 300 per cent over the period 1999-2009. ${ }^{2}$ Similar growth patterns can be observed with respect to trading value, number of listed companies and market capitalisation as a percentage of GDP. This paper investigates the effects of market liberalisation on the interdependence and stability of these four South Asian stock markets. In particular, it examines whether the patterns of stock return co-movement and risk spillover among Bangladeshi, Indian, Pakistani and Sri Lankan equities changed after the establishment of SAFE and the 2008 Global Financial Crisis.

According to the substantive literature, market deregulation may result in various benefits. For example, Henry (2000) argues that, in a post-liberalisation period, both Latin American and Asian developing markets experience a growth in investment and a decrease in the cost of capital within a country. These results are supported by Kim and Singal (2000) who document that stock market liberalisation not only attracts foreign investors but also results in the development of the capital market, real economic growth and greater linkages among international equity prices.

However, the extent of any linkages among stock markets may have negative implications for domestic economic activity and international investors. Strong linkages among markets may make them more susceptible to international shocks such as 9/11 (Singh et al. 2010) and regional or global financial crises An external shock which affects one market may be transmitted to another because of spillover effects. A number of authors also suggest that greater linkages among stock markets following a policy of liberalisation are associated with increased volatility (a measurement of risk) due to the "destabilising effect" of foreign investors (Singh 1997; Kassimatis 2002; Jayasuriya 2005). For example, Jayasuriya (2005) finds increased volatility in Colombia, Pakistan and Venezuela in a period after barriers to foreign

\footnotetext{
1 In these agreements, the four countries of Bangladesh, India, Pakistan and Sri Lanka are members, together with Bhutan, the Maldives and Nepal.

2 The Dhaka Stock Exchange (DSE), the Bombay Stock Exchange (BSE), the Karachi Stock Exchange (KSE) and the Colombo Stock Exchange (CSE) increased by 717.1, 538.8, 377.0 and 413.4 per cent, respectively.
} 
investment were dismantled. Nevertheless, Jayasuriya (2005) documents that volatility decreased after liberalisation in Argentina, Brazil, India, Korea, Malaysia, Mexico and Nigeria, while no change in volatility is documented for Chile, Greece, Jordan, the Philippines, Taiwan, Thailand, Turkey and Zimbabwe after their economies were opened up. Finally, it is suggested that linkages between markets may indicate that pricing inefficiency is present; spillovers may offer profitable arbitrage opportunities for investors since equity prices in one market may not be efficient with respect to return or risk changes that occur in other markets.

From the literature, existing studies that have investigated linkages in the South Asian region are fairly dated and do not take account of the impact of the foundation of SAFE as well as the 2008 Global Financial Crisis on the markets' sensitivity to external shocks-especially from the perspective of volatility spillovers. Yet, investigations of transmission mechanisms among stock markets from the perspective of volatility are as important as those that focus on return for a number of reasons. First, the finding of volatility spillovers (and changes in spillovers) among markets potentially represents evidence against market efficiency (Harris and Pisedtasalasai 2006) and the vulnerability of markets to external shocks. Second, an investigation of transmission mechanisms may explain how the stability and interdependence of these markets changed after liberalisation and indicate whether there was financial contagion in this region after the world economy faced a remarkable financial crisis in 2008 and economic recessions in several countries since then. Any changes in market volatility spillover and return correlations might require investors to rebalance their equity portfolios. Finally, an examination of changes in volatility transmission may help asset-pricing models, which rely on estimates of conditional volatility: for example, option pricing, portfolio optimisation and hedging (Hassan and Malik 2007). To the best of our knowledge, no study has previously studied whether the setup of SAFE affected interdependence among these four stock markets and led to financial contagion within the region during the global economic recession.

The current study focusses on the South Asian emerging markets of Bangladesh, India, Pakistan and Sri Lanka; these markets have largely been ignored in the existing literature when studying the topic of volatility transmission in the pre- and post-crisis periods. For example, Chow (2017) examines data for 10 Asian countries including China, Hong Kong, Indonesia, Japan, Korea, Malaysia, the Philippines, Singapore, Taiwan and Thailand when studying spillovers from the USA and the UK. The study finds that a rise in volatility is not temporary due to contagion during a crisis but reflects a more permanent increase in the volatility transmissions from developed to emerging markets. ${ }^{3}$ The results of the current study add to the findings of Chow (2017) by studying different markets and focussing on volatility transmission within the Southeast Asian region. The current work also builds upon the findings of Hung (2019); they investigate five Asian markets including China, Vietnam, Singapore, Thailand and Malaysia by employing the GARCH-BEKK model. The study finds strong evidence of volatility spillover from the Chinese market to the four Southeast countries. We

\footnotetext{
${ }^{3}$ Indeed, the Asian markets were found to have experienced higher volatility transfers in the post-crisis period.
} 
examine spillovers among four other nations in this region and add to our understanding of linkages among equity markets in this part of Asia.

The current paper aims to fill a gap in the literature by investigating the intercountry relationship of stock returns and volatility among the stock markets of Bangladesh, India, Pakistan and Sri Lanka over the period from 1993 to 2015. The sample period is disaggregated into three sub-periods: before the establishment of SAFE (1 January 1993-31 December 1999), after the establishment of SAFE and before the 2008 Global Financial Crisis (1 January 2000-12 September 2008) and after the occurrence of the Global Financial Crisis (20 March 2009-31 December 2015). Unlike prior research, we identify risk transmitters and risk recipients in the region for each of the three periods by applying the Baba, Engle, Kraft and Kroner's Multivariate Generalised Autoregressive Conditional Heteroscedasticity (MGARCH-BEKK) model with time-varying correlation to investigate changes in dynamic inter-relationships among these four South Asian stock markets' returns.

The relationships between the returns in the four countries are examined in a number of ways throughout the current paper. First, the long- and short-run dynamic relationships between the four markets are investigated using the multivariate Johansen cointegration technique and Vector Error Correction Model (VECM); these techniques are employed to study the data for the whole sample period as well as for three sub-periods including the periods before and after the establishment of SAFE and after the 2008 Global Financial Crisis. With the establishment of SAFE, one might expect that equity returns in each country might become more linked as regulatory differences between each nation's stock market were reduced. When analysing the returns, the data are tested for shocks and volatility spillovers using the GARCH-BEKK model; this model is used to investigate the return, variance and covariance among the sample markets in more detail. Finally, principal components analysis is employed to break the data into sample periods. We find that, after the establishment of SAFE, the interactions among the markets increased through volatility spillovers, but decreased through shock spillovers. In addition, there were more shock and volatility spillovers in the last sub-period, indicating that risk transmission across countries increased during the period of uncertainty. In particular, the Indian stock market was a risk spreader in South Asia after the setup of SAFE and its influence on the regional stock markets increased even further after the 2008 Global Financial Crisis.

The remainder of the paper is organised as follows. Section 2 briefly outlines the existing literature relevant to the topic of return and volatility spillover effects. Section 3 describes the data and reports the preliminary findings based on the principal components analysis. Section 4 discusses the model estimation and empirical results. Finally, Sect. 5 offers a number of concluding observations.

\section{Literature review}

The issue of integration among international stock markets is the focus of a great deal of research. In particular, research in the area seeks to investigate whether turmoil which occurs in one market has consequences for share prices in other markets 
(Arshanapalli and Doukas 1993; Click and Plummer 2005; Wang et al. 2005; Iqbal et al. 2012; Li and Giles 2015; Baumöhl et al. 2018; BenSaïda et al. 2018; Caloia et al. 2018; Davidson 2019; Jain and Sehgal 2019; Newaz 2019). Numerous studies investigate the extent of any interdependence among equity markets especially after the October 1987 stock market crash and the 1997 Asian crisis, which affected not only US and Asian equities but also transmitted shocks to other markets throughout the world (Wang et al. 2005). In addition, liberalisation policies, which have been adopted by various countries in order to permit capital to flow more freely among markets, suggest that this topic is of growing importance. Indeed, advances in communication technologies have improved information processing and enhanced the possibilities for national financial markets to react quickly to new information from international stock exchanges; as a result, financial shocks may be transmitted without delay from one country to another.

Most of the previous studies that investigate the integration of stock exchanges focus on developed markets (Hamao et al. 1990; Theodossiou and Lee 1993; Koutmos and Booth 1995; Kanas 1998; BenSaïda et al. 2018; Caloia et al. 2018); only a relatively small number investigate emerging stock markets. In addition, a majority of the studies that investigate the inter-relationships between emerging markets concentrate on countries in Latin America, Eastern Europe, East Asia and the Middle East (Chen et al. 2002; Gilmore and MacManus 2002; Syriopoulos 2004; Click and Plummer 2005; Diamandis 2009; Vo and Ellis 2018; Davidson 2019; Panda et al. 2019). Research on the linkages among the emerging markets of the South Asian region is limited. Furthermore, the limited literature on South Asian markets is also typically carried out using the cointegration framework and, as such, ignores other aspects of security performance such as risk (Narayan et al. 2004; Lamba 2005). However, Li and Majerowska (2008) argue that if markets are integrated, an anticipated event in one market will influence not only the return but also the volatility in other markets.

Another strand of the literature focuses on whether the level of integration among stock markets has changed over time or after the occurrence of international events. For example, Bekaert and Harvey (1995) find that integration among markets increases over time. In addition, Arshanapalli and Doukas (1993) argue that, after the October 1987 crash, the degree of international co-movement among share prices increased significantly. Similarly, Masih and Masih (2004) report that the lead-lag relationships among equity indices changed significantly following the stock market crash of October 1987. Similarly, Click and Plummer (2005) document that integration among the Association of South East Asian Nations (ASEAN) countries increased after the 1997 Asian crisis. Some recent studies focus on regional blocs of countries like the European Union (EU), ASEAN and China and countries along the "Belt-and-Road". They document that integration among stock markets increased after the establishment of trading blocs (Dedi and Yavas 2016; Virk and Javed 2017; Chevallier et al. 2018; Lu et al. 2019).

Several studies investigate linkages among stock markets in terms of both return and volatility spillovers and those that do so tend to employ univariate or bivariate GARCH approaches (Hamao et al. 1990; Liu and Pan 1997; Kanas 1998; and Wang et al. 2005). Indeed, most of these studies focus on return and volatility transmission 
from developed markets; hence, these studies are predominantly occupied with testing the influence of markets in developed countries on other stock exchanges (Hamao et al. 1990; Bekaert and Harvey 1995; Karolyi and Stulz 1996; Li and Giles 2015). In addition, the few studies that consider emerging markets (Wang et al. 2005; Iqbal et al. 2012) tend to consider each pair of markets in isolation without recognising that volatility spillovers from several markets may affect the conditional variance of returns in one country. ${ }^{4}$

Some studies on spillover effects use MGARCH models to examine the interaction between the return and volatility of several countries (Chou et al. 1999; Scheicher 2001; Worthington and Higgs 2004; Conrad et al. 2011; MacDonald et al. 2018) and internal linkages among various sectors (Harris and Pisedtasalasai 2006; Hassan and Malik 2007; Majumder and Nag 2018; Alomari et al. 2018) or among stock markets within an economy (Weber and Zhang 2012). For example, Chou et al. (1999) uncover evidence of both return and volatility spillovers from the US market to the Taiwanese market during 1991-1994. In a subsequent European study, Scheicher (2001) investigate the regional and global integration of stock markets in terms of return and volatility for Hungary, Poland and the Czech Republic with the S\&P Actuaries World Index by using an MGARCH model which assumes a constant conditional correlation. The results reveal that only regional volatility spillovers exist and that these three Eastern European emerging markets are integrated with the global market in terms of returns only. On the other hand, Conrad et al. (2011) model the volatility of the national stock market indices of Canada, France, Germany, Hong Kong, Japan, Singapore, the UK and the USA using univariate, bivariate and trivariate fractionally integrated asymmetric power ARCH models with a constant conditional correlation assumption. They find that the multivariate processes are superior to the univariate models and thus are generally preferred to their nested competitors.

While early studies employ univariate GARCH models or MGARCH models with a constant conditional correlation assumption, more recent investigations use the MGARCH-BEKK model which allows the conditional correlation to be timevarying (Li 2007; Malik and Hammoudeh 2007; Li and Majerowska 2008; Joshi 2011; Li and Giles 2015). For example, Worthington and Higgs (2004) find a spillover of returns and/or volatility from Japan and Hong Kong to the Asian emerging stock markets of Indonesia, Korea, Taiwan, the Philippines and Thailand. They further argue that the influence of a stock market's own past volatility on current variability is greater than the volatility spillover from other markets. More recently, Joshi (2011) investigates return and volatility spillovers among the stock market indices of India (BSE), Hong Kong (Hang Seng), Japan (N225), China (SSE), Indonesia

\footnotetext{
${ }^{4}$ Wang et al. (2005) investigate return and volatility spillovers from the USA and Japan to India, Pakistan and Sri Lanka using a univariate EGARCH model to distinguish the impact of global (the US) and regional (Japan) factors on the emerging markets of the region. However, one serious limitation of univariate volatility models is that they model the conditional variance of each series independently of all other series. Univariate models may therefore be mis-specified for volatility spillovers where volatility changes in one market are followed by changes in volatility in another market. Moreover, in finance, covariances are of interest as well as the variances of the individual series.
} 
(JKSE) and Korea (KSII). ${ }^{5}$ Joshi (2011) finds both a unidirectional and bidirectional return spillover among the markets. Specifically, he finds (i) a unidirectional volatility spillover from the Hang Seng index to the BSE index as well as the JKSE index; and (ii) a bidirectional volatility spillover between the BSE index and the Hang Seng index and the markets of almost all other Asian countries he examines. Unlike these studies, this paper focuses on the effects of regional financial liberalisation and the global economic recession on stock return comovement and risk spillover within South Asia, where studies are relatively scarce.

\section{Data and preliminary analysis}

This paper examines weekly stock returns of four South Asian markets during the period from January 1993 to December $2015 .{ }^{6}$ The total sample period is divided into three sub-periods. The first sub-period is before the establishment of SAFE (1 January 1993-31 December 1999). The second sub-period is the global economic boom period (1 January 2000-12 September 2008) during which South Asian markets were reformed and operations standardised after the establishment of SAFE. The third sub-period is the post-crisis period (20 March 20097-31 December 2015). In this period, many nations faced economic recession and deflation and, to cope with these problems, several policies such as quantitative easing and negative interest rates were implemented; in addition, this period was characterised by political unrest and wars in several Islamic states. These events affected the economies of South Asian countries due to a significant reduction in exports to developed countries which are a major destination for goods/services and the net outflow of foreign capital from stock markets in order to reduce risk exposures in emerging markets. The sub-period analysis in this paper facilitates an examination of market stability and changes in interdependences among South Asian stock markets during periods of regional stock market development and global growth and contraction. The interaction among the South Asian markets may have been accelerated due to the financial co-operation between countries after becoming members of SAFE and the crisis

\footnotetext{
5 The abbreviations stand for the Bombay Stock Exchange (BSE), the Nikkei 225 (N225), the Shanghai Stock Exchange (SSE), the Jakarta Composite Index (JKSE) and the Korean Stock Exchange (KSII).

6 The present study focuses on the integration of the emerging South Asian markets linked by SAFE. Future research could include the developed markets of the USA and UK to examine their level of integration and volatility spillovers with markets in the Southeast Asian region.

7 During 15 September 2008 to 19 March 2009, there was a mix of local and global shocks, such as the bankruptcy and bailout of several financial institutions in the USA and UK, the end of civil war in Sri Lanka in February 2009, the Sri Lankan government's rejection of conditions attached to an IMF emergency loan in March 2009, a protest in Pakistan during 9-17 March 2009, and news release about the expectation of global economic recession on 19 March 2009. The change in co-movement of stock returns in this turbulent period is analysed in this paper using principal components analysis (PCA). However, the period is excluded from the cointegration and $\mathrm{MGARCH}$ analyses because the number of observations ( 24 weekly observations) is too few for modelling.
} 
contagion when shocks in the developed markets spread across the globe (Wang et al. 2005). ${ }^{8}$

The choice of these markets is determined mainly by the availability of data, the relatively large size of these markets in the region, and the expected financial and economic linkages between these countries. Stock exchanges in India and Sri Lanka date back more than a century; the Bombay Stock Exchange (BSE) was established in 1875, while the Colombo Stock Exchange (CSE) commenced operations in 1896. The other two major exchanges are relatively newer; the Karachi Stock Exchange (KSE) was established in 1947 after Pakistan gained independence, while the Dhaka Stock Exchange (DSE) was formed in 1954 as the East Pakistan Stock Exchange Association Limited; it was renamed the Dhaka Stock exchange in 1964. The Indian stock market is the largest market in the region and was the seventh largest market in the world in terms of market capitalisation as at the end of 2018. Bloomberg ranked the KSE as the third best performing market in 2014. The stock exchanges of Bangladesh and Sri Lanka are very similar in size. The higher turnover ratios in India and Pakistan mean that securities are more actively traded in these countries than in Bangladesh and Sri Lanka. According to the value of shares traded, India was ranked 15th among the world markets in 2015 with a turnover ratio of 50.9 percent.

Although these stock markets were established over a considerable period of time, they did not play a prominent role in the economic development of their countries until the respective governments started a programme of deregulation and liberalisation in the early 1990s (Bekaert et al. 2003). The process of liberalisation started in 1991 in the two smallest markets of the region, Bangladesh and Sri Lanka; the domestic markets for savings in these countries were insufficient to fund a growing demand for investment by locally listed firms. Liberalisation in Pakistan followed in February 1992, while India was the last to permit foreign investors to invest directly in listed companies in November 1992. Although the practice of liberalisation started at around the same time for the sample countries, the process varied from one country to another. For example, Bangladesh initially focused on nonresidents, while Sri Lanka only allowed investment in companies incorporated abroad. ${ }^{9}$ Following liberalisation, the markets have performed well and the number of listed companies has increased significantly. The current paper therefore aims to evaluate the interdependence between the four South Asian stock markets, which might have been established since 1993. Further, it takes account of the regional financial and trade co-operations that were introduced in the early 2000s; for example, the establishment of SAFE in

\footnotetext{
${ }^{8}$ King and Wadhwani (1990) argue that fundamental variables in individual countries have largely failed to provide an explanation for the international transmission of shocks. Many researchers follow their notion of market contagion. They define contagion as a significant increase in correlation coefficients across global financial markets. In addition, Charles and Darne (2006) suggest that the US market behaves as a leader and influences other markets of the world, supporting the argument of more spillovers in the event of a US crisis.

9 As a result of the introduction of these liberalisation policies, all four countries opened their stock markets to foreign investors, introduced various rules for the protection of small investors, implemented measures to control insider trading, strengthened their regulatory bodies and introduced computer-based depository systems (Goldberg and Dilgado 2001; Bekaert et al. 2003; Narayan et al. 2004).
} 
January 2000. Since then, a period of political stability and peace among the countries has also attracted more foreign investment to the region (Khalid and Rajaguru 2004). Thus, it is interesting to examine whether the co-movement of stock market returns in South Asia shifted and the role of particular markets in volatility spillovers across these four countries changed after these four markets became members of SAFE and when the 2008 Global Financial Crisis occurred.

Weekly data on the Dhaka All Share Price Index (BDSE), the Indian BSE National Price Index (INSE), the Karachi SE-100 Price Index (PKSE) and the Colombo All Share Price Index (SLSE) are obtained from Datastream. All index prices are obtained in local currencies. ${ }^{10}$ The Dhaka and Colombo All Share Price Indices consist of all the shares traded on the stock exchanges. The Indian BSE National Index comprises 100 equities listed on five major Indian stock exchanges, namely, Mumbai, Calcutta, Delhi, Ahmedabad and Madras. The Karachi 100 index includes the largest 100 companies listed on the stock exchange, covering about 85.0 per cent of the total market capitalisation of the exchange. The use of weekly data is preferred over daily and monthly data to mitigate against the potential effects of any noise which may be present in the daily data and to avoid any data shortage problem which may arise with monthly data (Chuang et al. 2007). ${ }^{11}$

Table 1 shows the distribution of stock market returns in the four South Asian markets. The mean values indicate that stock index returns in the four sample markets are very low during the first sub-period. The skewness measures also highlight that BDSE returns are significantly positively skewed, whereas PKSE returns are significantly negatively skewed in the first sub-period, indicating that BDSE (PKSE) returns tend to be higher (lower) than the mean value in the period analysed. The distribution of stock returns changes after the establishment of SAFE. Stock returns in South Asia increase, and market risk in India and Sri Lanka increases slightly, while risk in the Bangladeshi and Pakistani stock markets declines significantly. In addition, all series except SLSE are negatively skewed in the second sub-period, suggesting that there is more than a 50.0 per cent chance that stock returns in the three markets are higher than the average value. After the 2008 Global Financial Crisis, South Asian stock markets except for BDSE experience higher returns and lower risk indicating the safe haven investment potential of these markets. However, it is notable that the returns of these South Asian stock markets exhibit positive skewness with the exception of those for PKSE where there is, in fact, less than a 50.0 per cent chance that investors could gain more than the mean value reported in Table 1. Further, the distributions of stock returns are leptokurtic relative to the normal distribution across all countries and sub-periods, resulting in a rejection of the Jarque-Bera normality test.

\footnotetext{
${ }^{10} \mathrm{Li}$ and Majerowska (2008) argue that when stock indices are in local currencies, their changes are restricted to the stock process only and avoid any distortions induced by the currency fluctuations of the countries.

11 Roca (1999) argue that the use of daily data can give rise to problems of noise, nonsynchronous trading and day-of-the week effects. Tay and Zhu (2000) report that they use weekly data to avoid potential problems with nonsynchronous trading and stale quotes which are possible reasons for the inconsistent results documented in earlier studies.
} 
The findings above suggest that the distributions of stock returns in South Asian markets changed over the past two decades and a GARCH estimation approach should be employed because of the nonnormal fat-tailed distributions. A GARCH model is capable of dealing with data which have the features outlined in Table 1. For example, Li (2007), Li and Majerowska (2008) and Joshi (2011) report that, when modelling with GARCH, the nonzero skewness statistics indicate that an $\mathrm{ARCH}$ order higher than one is required in the conditional variance equation. Indeed, an $\operatorname{MGARCH}(1,1)$ model may be preferred to an $\mathrm{ARCH}$ (p) model when examining volatility spillover effects for the sake of parsimony. In this paper, the change in pattern of market risk spillover across stock markets is examined by employing a tetra-variate GARCH-BEKK framework.

In addition to shifts in stock returns and their volatilities, the co-movement of South Asian stock returns also changes over the period analysed. Figure 1 illustrates the principal components analysis (PCA)'s orthonormal loadings for three different sub-periods and a turmoil period between sub-periods 2 and 3 (15 September 2008-19 March 2009) which reflect the co-movement of stock index returns in all four markets in these periods. The change in orthonormal vectors indicates a change in co-movement among the markets analysed. During 1993-1999, the Sri Lankan and Pakistani stock market returns co-move closely, while the co-movement between stock market returns in Bangladesh and those in the other three markets is very weak. The PCA loadings show that the comovement of these four stock markets improves after the establishment of SAFE, especially the co-movement between Bangladeshi and Indian stock market returns. The interdependence between these markets becomes weaker during the economic and political turmoil that occurred between 15 September 2008 and 19 March 2009; Pakistan becomes independent of the regional market, while the co-movement between stock market returns in Bangladesh and those in India, as well as Sri Lanka, appear to be weaker. However, the co-movement between Sri Lankan and Indian returns becomes stronger again during the 2008 Global Financial Crisis. The co-movement changes again after 20 March 2009 when the developed markets such as the USA, UK, EU and Japan experienced an economic downturn; Pakistani stock market returns become more interdependent with Indian and Sri Lankan stock market returns. ${ }^{12}{ }^{13}$

\footnotetext{
12 PCA is used to look at the relationship between the current returns in one market and lagged returns in other countries while taking account of any common elements that influence these lagged returns. The resulting PCs are orthogonal which should eliminate any multicollinearity among the lagged returns from the different countries and improve the inferences that can be drawn from the analysis. The loadings for the PCs indicate the degree to which the markets co-move; these are estimated for the different subperiods studied. Those PCs with eigenvalues below a certain threshold are excluded when determining the number of components to be retained in the analysis. In the current investigation, two components explain most of the co-movements in the lagged returns across the different sub-periods; hence these two components are retained for inclusion in the model. The two components show similar loadings for all sub-periods except the crisis period, indicating that dividing the data into three sub-period is justified. In addition, the PCA indicates that these two factors account for 59.1 per cent for sub-period 1 lagged returns, 56.3 per cent for the second sub-period lagged returns and 60.3 per cent for the third sub-period lagged returns; these percentages indicate a substantial amount of long-run movement in returns.

13 Structural break tests are also conducted, and they indicate breaks in the data series along the lines of the events-based approach used in this paper.
} 
Table 1 Descriptive statistics of the weekly return series

\begin{tabular}{lrccc}
\hline \multicolumn{1}{c}{ Bangladesh } & India & Pakistan & Sri Lanka \\
\hline Sub-period (1) & & & & \\
Mean & 0.0010 & 0.0017 & 0.0003 & -0.0002 \\
SDev & 0.0467 & 0.0350 & 0.0400 & 0.0281 \\
Skewness & $1.3413^{*}$ & -0.2138 & $-0.4917^{*}$ & 0.1377 \\
Kurtosis & $14.3663^{*}$ & $3.6220^{*}$ & $5.1227^{*}$ & $5.0659^{*}$ \\
Jarque-Bera & $2074.25^{*}$ & $8.6651^{*}$ & $83.234^{*}$ & $66.065^{*}$ \\
Sub-period(2) & & & & \\
Mean & 0.0035 & 0.0022 & 0.0040 & 0.0032 \\
SD & 0.0331 & 0.0365 & 0.0368 & 0.0285 \\
Skewness & $-0.5703^{*}$ & $-0.6866^{*}$ & $-0.6770^{*}$ & $0.8548^{*}$ \\
Kurtosis & $28.4338^{*}$ & $4.7536^{*}$ & $5.5464^{*}$ & $9.1187^{*}$ \\
Jarque-Bera & $12234.4 *$ & $93.636^{*}$ & $157.00^{*}$ & $761.82^{*}$ \\
Sub-period (3) & & & & \\
Mean & 0.0020 & 0.0034 & 0.0049 & 0.0041 \\
Std. Dev & 0.0359 & 0.0263 & 0.0226 & 0.0223 \\
Skewness & $0.5609^{*}$ & $0.5390^{*}$ & -0.0925 & $0.9443^{*}$ \\
Kurtosis & $10.6201^{*}$ & $6.5931^{*}$ & $4.9041^{*}$ & $5.8834^{*}$ \\
Jarque-Bera & $877.549^{*}$ & $208.16^{*}$ & $54.138^{*}$ & $175.75^{*}$ \\
\hline
\end{tabular}

Table 1 summarises descriptive statistics for the four South Asian stock markets included in the study over the three sub-periods January 1993-December, 1999, January 2000-September 2008 and March 2009-December 2015. In particular, the table shows the mean (Mean), the standard deviation (SD), the Kendall-Stuart measures of skewness (Skewness) and kurtosis (Kurtosis) and the JarqueBera test (Jarque-Bera) for normality. An *indicates significance at the five per cent level

\section{Cointegration analysis}

Using regression analysis for nonstationary variables leads to spurious results about the estimated parameters and the degree of association. Therefore, before testing for cointegration, the order of integration of the stock prices must be determined. The augmented Dickey-Fuller (ADF) (1979) and the Phillips and Perron (P-P) (1988) tests are used to test for a unit root. Table 2 reports the results for both the ADF and $\mathrm{P}-\mathrm{P}$ unit root tests in levels and in the first differenced form for the stock indices of the four South Asian markets. The test results show that the null hypothesis that each of the stock indexes has a unit root in level form is not rejected for all of the four markets over the four time periods examined. In their first differenced form, the null hypothesis of a unit root in each of the series is rejected for all markets. Therefore, the series are I(1) and, hence, cointegration analysis can be employed.

The concept of cointegration was first introduced by Granger in 1981. Later, Engle and Granger (1987) suggest a procedure for testing the hypotheses of cointegration. They propose a simple two-step procedure for testing cointegration 
Sub-Period (1)

\section{Orthonormal Loadings}

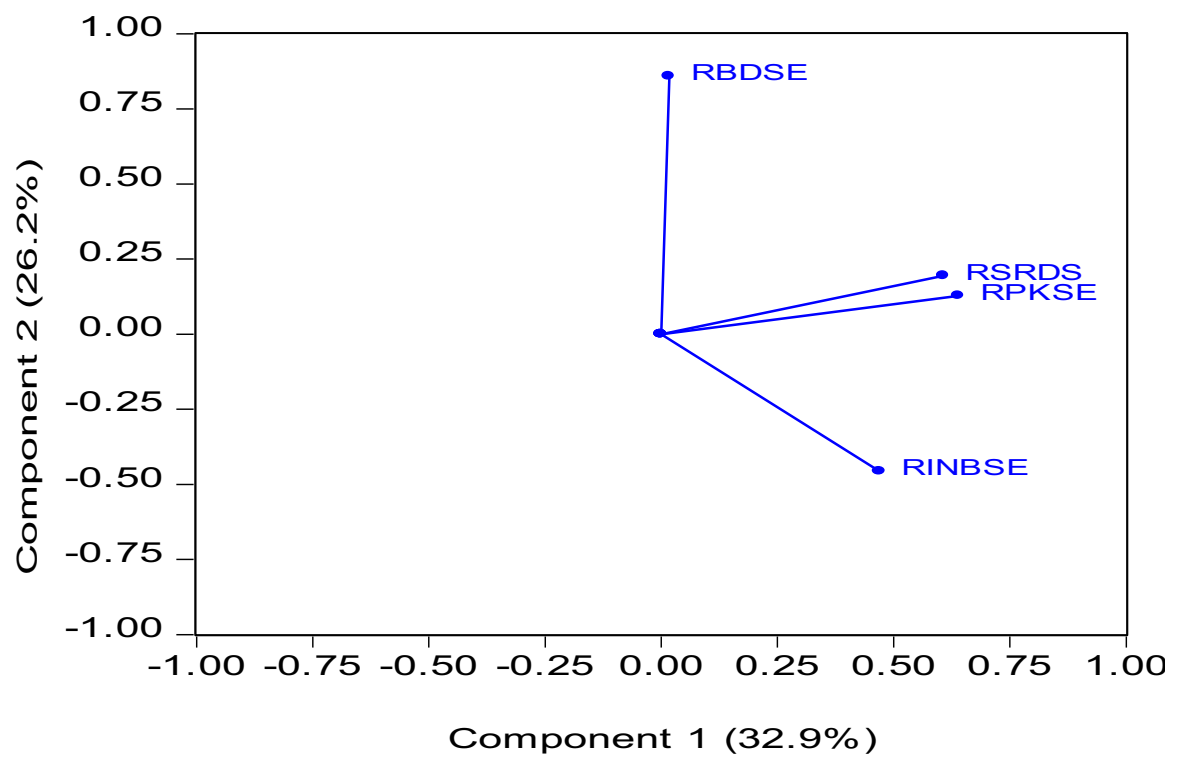

Sub-Period (2)

Orthonormal Loadings

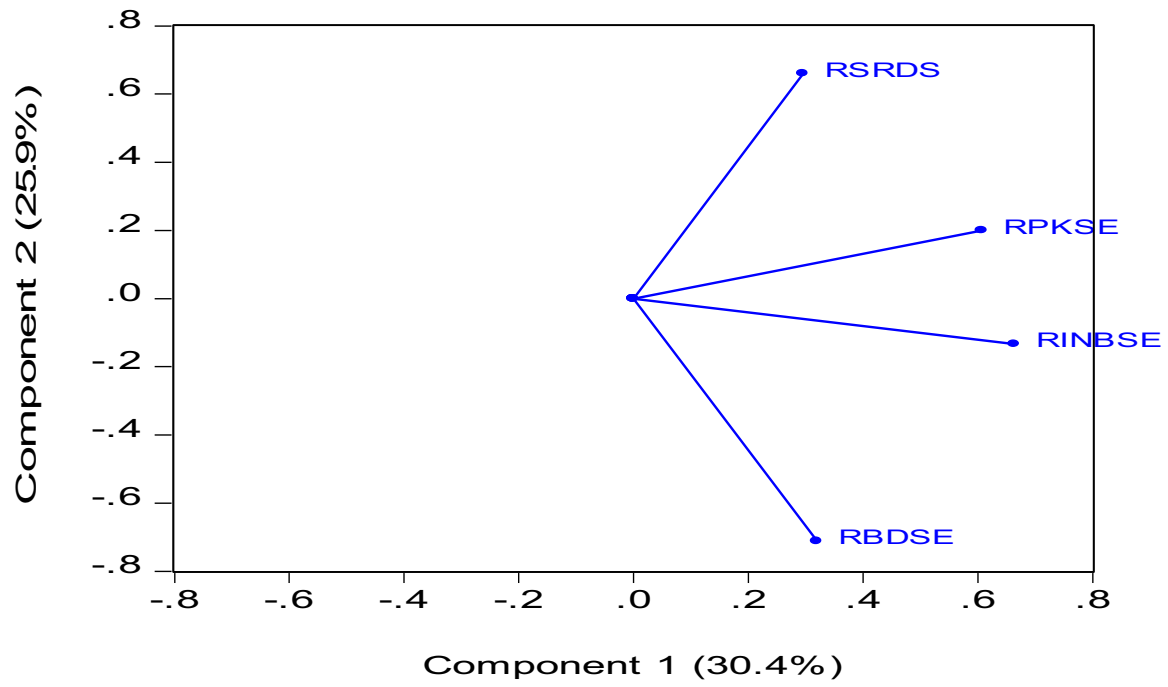

Fig. 1 PCA Orthonormal Loadings. The abbreviations RBDSE, RINBSE, RPKSE and RSRDS stand for the return of the Bangladesh Dhaka Stock Exchange, the return of India Bombay Stock Exchange, the return of the Pakistan Karachi Stock Exchange and the return of the Sri Lankan stock exchange, respectively 
15 September 2008 - 19 March 2009

\section{Orthonormal Loadings}

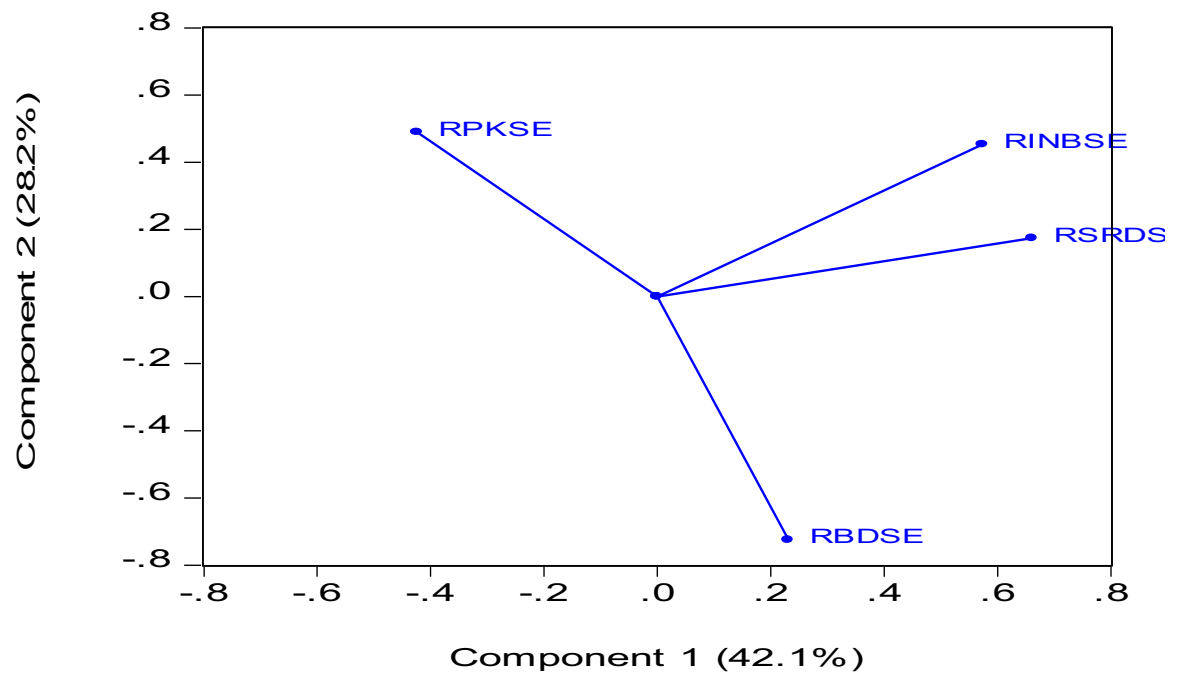

Sub-Period (3)

\section{Orthonormal Loadings}

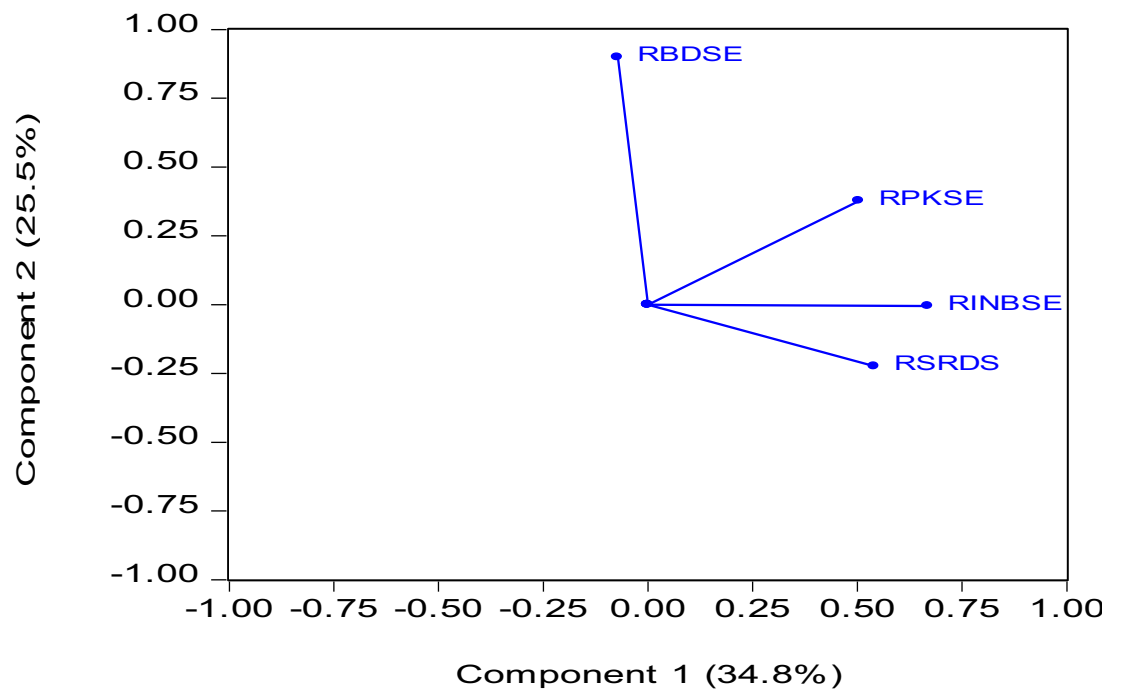

Fig. 1 (continued)

using the ordinary least squares (OLS) method. However, this approach is criticised as problematic because of possible errors arising from the two-step process 
Table 2 Unit root test results

\begin{tabular}{|c|c|c|c|c|}
\hline \multirow[t]{2}{*}{ Country } & \multicolumn{2}{|l|}{$\mathrm{ADF}$} & \multicolumn{2}{|l|}{$\mathrm{P}-\mathrm{P}$} \\
\hline & Level & 1st Diff & Level & 1st Diff \\
\hline \multicolumn{5}{|c|}{ Test results for the entire period: 01/01/1993 to 31/12/2015 } \\
\hline Bangladesh & -1.09 & $-8.23 *$ & -1.03 & $-32.47 *$ \\
\hline India & 0.24 & $-15.49 *$ & 0.26 & $-32.14^{*}$ \\
\hline Pakistan & 0.67 & $-3.69 *$ & 1.97 & $-29.90^{*}$ \\
\hline Sri Lanka & -0.33 & $-4.92 *$ & 0.24 & $-26.89^{*}$ \\
\hline \multicolumn{5}{|c|}{ Test results for sub-period (1): 01/01/1993 to 31/12/1999 } \\
\hline Bangladesh & -0.69 & $-5.39 *$ & -2.26 & $-14.36^{*}$ \\
\hline India & -0.87 & $-17.57 *$ & -1.04 & $-17.59 *$ \\
\hline Pakistan & -1.75 & $-15.96^{*}$ & -1.64 & $-15.23 *$ \\
\hline Sri Lanka & -1.63 & $-13.31 *$ & -1.67 & $-13.46^{*}$ \\
\hline \multicolumn{5}{|c|}{ Test results for sub-period (2): 01/01/2000 to 12/09/2008 } \\
\hline Bangladesh & -0.69 & $-4.22 *$ & -0.21 & $-20.02 *$ \\
\hline India & 1.46 & $-4.09 *$ & -0.50 & $-20.34 *$ \\
\hline Pakistan & -1.04 & $12.27 *$ & 0.56 & $-20.01 *$ \\
\hline Sri Lanka & -0.40 & $-5.44^{*}$ & -0.60 & $-18.02^{*}$ \\
\hline \multicolumn{5}{|c|}{ Test results for sub-period (3): 20/03/2009 to 31/12/2015 } \\
\hline Bangladesh & -2.42 & $-7.02^{*}$ & -2.43 & $-18.45^{*}$ \\
\hline India & -2.13 & $-9.61^{*}$ & -2.13 & $-17.37^{*}$ \\
\hline Pakistan & 0.10 & $-16.08^{*}$ & -0.27 & $-15.89^{*}$ \\
\hline Sri Lanka & -2.64 & $-3.36^{*}$ & -2.75 & $-14.23 *$ \\
\hline
\end{tabular}

Test critical values: -2.57 at the one per cent level and -1.94 at the five per cent level. The table shows unit root test results using the augmented Dicky-Fuller (ADF) and the Phillips-Perron (P-P) tests. The table summarises the results for the entire period, and each of the three sub-periods. The critical values are based on MacKinnon (1996). An *indicates significance

and inconsistency in results. These problems with the Engle and Granger two-step procedure are overcome by Johansen (1988) and Johansen and Juselius (1990) who estimate the cointegrating vector using the maximum likelihood estimation technique. They provide a method of estimating a multivariate VECM based on a vector autoregressive VAR $(k)$ model with Gaussian errors and its implications on equilibrium. Their process has the advantage of capturing both long- and short-term relationships of a system based on the series being examined.

Let $X_{t}$ be a vector of four stock market indices which are individually nonstationary and are integrated of the same order, e.g. I(1). A VAR (k) model can be written as:

$$
X_{t}=\mu+A_{1} X_{t-1}+A_{2} X_{t-2}+A_{3} X_{t-3}+\cdots+A_{k} X_{t-k}+\Sigma_{t}
$$

where $X_{t}$ is an $4 \times 1$ vector of I(1) stock index series, $A_{k}$ is a $4 \times 4$ coefficient matrix, $t=1,2,3, \ldots . T$ and $\Sigma_{t}$ is a $4 \times 1$ vector of white noise error terms. The VAR $(k)$ model in (1) can be written as a VECM which takes the form: 


$$
\Delta X_{t}=\mu+\Gamma_{1} \Delta X_{t-1}+\Gamma_{2} \Delta X_{t-2}+\Gamma_{3} \Delta X_{t-3}+\cdots+\Gamma_{k-1} \Delta X_{t-k}+\Pi X_{t-k}+\Sigma_{t}
$$

where $\Delta$ is a first difference operator, $\Gamma$ is an $4 \times 4$ coefficient matrix representing the short-term dynamics and is defined as:

$$
\Gamma_{m}=-I+\sum_{i=1}^{m} A_{i} \quad m=1,2,3, \cdots k-1
$$

and $\Pi$ is an $4 \times 4$ matrix of coefficients representing long-term dynamics and is defined as:

$$
\Pi=-I+\sum_{i=1}^{k} A_{i}
$$

$\Pi$ is the long-term coefficient matrix, and its rank $r$ determines the number of cointegrating vectors. If $\Pi$ has a rank $r$, then there are $r$ cointegrating relationships between the $X_{t}$ or $4-r$ common stochastic trends. The number of cointegration vectors shows the extent to which the stock markets in the study are integrated. If $\Pi$ has a rank of zero there are no stationary long-term equilibrium relationships among the elements of $X_{t}$. When $\Pi$ has a reduced rank such that $0<r<4$, there exist $r$ cointegrating vectors or $r$ relationships among the four markets. Johansen $(1988,1991)$ suggests two methods for estimating the number of cointegrating vectors; the trace test $\left(\lambda_{\text {trace }}\right)$ and the maximum eigenvalues test $\left(\lambda_{\max }\right) .{ }^{14}$ In this article, the critical values are based on those proposed by MacKinnon et al. (1999).

Table 3 documents the results of the cointegration tests for Eq. (1) based on the $\lambda_{\text {trace }}$ statistic and the $\lambda_{\max }$ eigenvalues statistic for the four South Asian countries of Bangladesh, India, Pakistan and Sri Lanka. Specifically, the table reports results for the entire period from January 1993 to December 2015, and for the three sub-periods (01/01/1993-31/12/1999; 01/01/2000-12/09/2008 and 20/03/2009-31/12/2015). The first column in this table shows the number of cointegrating vectors investigated, while the next three columns report the trace test values, the critical values for this test and the $\mathrm{p}$ value. The final three columns detail the statistics, the critical values and the $\mathrm{p}$ values for the $\lambda_{\max }$ test.

A visual inspection of the table reveals that, for the whole period, the null hypothesis $r=0$ can be rejected since the $\lambda_{\text {trace }}$ statistic of 37.37 for the South Asian countries is greater than the five per cent significance level. The $\lambda_{\max }$ test statistic has a value of 27.63 which is also higher than its critical value of 21.13 at the five per

\footnotetext{
${ }^{14}$ The $\lambda_{\text {trace }}$ statistic is a joint test of the null hypothesis that the number of cointegrating vectors is less than or equal to $r$ against a general or unspecified alternative hypothesis of more than $r$ cointegrating vectors. The $\lambda_{\max }$ statistic conducts a separate test on each of the eigenvalues. The null hypothesis in this case is that the number of cointegrating vectors is $r$ against an alternative that there are $r+1$ relationships. Both the $\lambda_{\text {trace }}$ and $\lambda_{\max }$ test statistics have nonstandard distributions, and their critical values depend on the values of $4-r$, the number of nonstationary components and whether constants and trends are included or not in each of the equations (Brooks 2014). For both of these tests, critical values are provided by Johansen and Juselius (1990), Osterwald-Lenum (1992) and MacKinnon et al. (1999).
} 
cent level of significance. Both tests indicate that the markets have two cointegrating vectors in the entire sample period since there is a failure to reject the null for values of $r>0$, but the null for $r>2$ can be rejected. The table also shows that the $\lambda_{\text {trace }}$ and $\lambda_{\max }$ test statistic values are lower than the five per cent significance level for the period from January 1993 to September 2008, suggesting that there is no evidence of cointegration among the markets during the first and second sub-periods. Such a finding suggests that the 1990s liberalisation did not lead to the convergence of South Asian equity markets. Indeed, Sect. 3 highlights that some barriers to equity investment may still have been present; these may have reduced any linkages between the stock markets and dissipated any relationships between equity returns. Finally, for the last subperiod, the $\lambda_{\text {trace }}$ Statistics are higher than their critical values at the five per cent level of significance for the null hypothesis of $r=0$ and $r=1$; the null is therefore rejected by the trace test and two cointegrating vectors are detected during the third sub-period. The cointegration test indicates two cointegrating vectors among the stock market indices of the South Asian region in the final subperiod, leading to the presence of two cointegrating vectors over the entire period from January 1993 to December 2015. The markets have a common trend in the long run which suggests that there may be less diversification benefits for international investors because of co-movement among the index returns. The results also suggest that integration among the region increased after the 2008 Global Financial Crisis - that is, the markets show more linkages after March 2009, which indicates that global events of importance may have had a common impact on the behaviour of these markets.

The multivariate Johansen cointegration test results reported in Table 3 indicate the presence of two cointegrating vectors. Both the $\lambda_{\text {trace }}$ and the $\lambda_{\max }$ tests confirm that a long-run relationship exists among these four markets-especially since 2009. ${ }^{15}$ The cointegration results in Table 3 indicate that the four markets have a tendency to co-move in the long run. However, in the short run, they may deviate from this equilibrium relationship. To further investigate the relationships among the four equity markets of South Asia, the VECM in Eq. (4) is examined. The intuition behind VECM analysis is that, when the markets are in equilibrium, part of the current changes in one market affects the tendency to respond to trends in returns from other countries being examined. The VECM is used to examine the short- and long-run relationships among the four markets. The VECM results are reported in Table 4, which shows the results for each market in the system. ${ }^{16}$ The top of each subsection of the table reports the short-run impact for a market of both lagged changes in its own values as well as lagged in the other three markets. The end of each subsection of the table indicates whether or not the error correction term (ECT) is significant at the five per cent level. ${ }^{17}$

\footnotetext{
15 The results for the sub-periods in the short run are not reported due to space considerations; they are similar in nature to the results reported here for the entire period. The sub-period results are available from the authors on request.

16 The lag selection is based on the AIC information criteria.

17 The ECT shows the long-run information because it is derived from the long-run cointegrating relationship (Chen et al. 2002).
} 
Table 3 Multivariate Johansen cointegration test results

\begin{tabular}{|c|c|c|c|c|c|c|}
\hline Rank & Trace test & Critical value & $p$ Value & Max test & Critical Values & $p$ Value \\
\hline \multicolumn{7}{|c|}{ Entire period: $01 / 01 / 1993$ to $31 / 12 / 2015$} \\
\hline 0 & $70.35^{*}$ & 47.87 & 0.00 & $32.98 *$ & 27.58 & 0.01 \\
\hline 1 & $37.37 *$ & 29.80 & 0.01 & $27.63 *$ & 21.13 & 0.01 \\
\hline 2 & 9.74 & 15.49 & 0.30 & 8.28 & 14.26 & 0.35 \\
\hline 3 & 1.46 & 3.84 & 0.23 & 1.46 & 3.84 & 0.23 \\
\hline \multicolumn{7}{|c|}{ Sub-period (1): 01/01/1993 to 31/12/1999 } \\
\hline 0 & 32.28 & 47.86 & 0.60 & 20.54 & 27.58 & 0.30 \\
\hline 1 & 11.73 & 29.80 & 0.94 & 8.22 & 21.13 & 0.89 \\
\hline 2 & 3.51 & 15.49 & 0.94 & 3.51 & 14.26 & 0.91 \\
\hline 3 & 0.01 & 3.84 & 0.94 & 0.01 & 3.84 & 0.94 \\
\hline \multicolumn{7}{|c|}{ Sub-period (2): 01/01/2000 to $12 / 09 / 2008$} \\
\hline 0 & 32.08 & 47.86 & 0.61 & 17.56 & 27.58 & 0.53 \\
\hline 1 & 14.52 & 29.80 & 0.81 & 11.61 & 21.13 & 0.59 \\
\hline 2 & 2.91 & 15.49 & 0.97 & 2.58 & 14.26 & 0.97 \\
\hline 3 & 0.33 & 3.84 & 0.57 & 0.33 & 3.84 & 0.57 \\
\hline \multicolumn{7}{|c|}{ Sub-period (3): 20/03/2009 to $31 / 12 / 2015$} \\
\hline 0 & $51.94 *$ & 47.86 & 0.02 & 20.36 & 27.58 & 0.32 \\
\hline 1 & $31.61 *$ & 29.80 & 0.03 & 18.54 & 21.13 & 0.11 \\
\hline 2 & 13.07 & 15.49 & 0.11 & 12.97 & 14.26 & 0.08 \\
\hline 3 & 0.09 & 3.84 & 0.76 & 0.10 & 3.84 & 0.76 \\
\hline
\end{tabular}

The table summarises the results obtained from conducting the multivariate Johansen cointegration test using data for the four South Asian stock markets. Specifically, the table details the results for the whole test period, and for each of the three sub-periods examined. Critical values are based on MacKinnon et al. (1999): An *denotes significance of the test statistic at the five per cent level

A visual inspection of Table 4 indicates that there are four panels-one for each of the four markets (with current returns as the dependent variable in the analysis) with the lagged returns from the same country as well as from the other three markets as independent variables. The first panel reveals that the Bangladeshi market is influenced by its own lagged returns with a significant coefficient of 0.07 . The $t$-statistics for each of the lagged changes in the other three markets shows that changes in Bangladeshi returns are not influenced by lagged returns in India, Pakistan or Sri Lanka over the previous weeks.

The second panel of Table 4 indicates that the Indian market is inefficient since it is influenced by its own lagged returns; the co-efficient of 0.07 is significant at the five per cent level. Lagged returns in the other three markets have no influence on current Indian equity price changes suggesting no spillovers from the Bangladeshi, Pakistani and Sri Lankan stock markets. Changes in the Indian market are only caused by its own variations in previous weeks' returns.

The third panel of the table reports the VECM results when the Pakistani market is the dependent variable. The results show evidence of a weak, long-run relationship between current Pakistani returns and lagged price changes for the rest of the 
Table 4 Vector error correction model results: whole period

\begin{tabular}{|c|c|c|c|c|}
\hline \multirow[t]{2}{*}{ Lag order (Weeks) } & \multirow{2}{*}{$\begin{array}{l}\text { Dependent market } \\
\Delta \text { BDSE }\end{array}$} & \multicolumn{3}{|c|}{ Independent markets } \\
\hline & & $\Delta \mathrm{INBSE}$ & $\Delta \mathrm{PKSE}$ & $\Delta$ SRLK \\
\hline \multirow[t]{2}{*}{1} & $0.07 *(2.47)$ & $0.12(1.86)$ & $0.01(0.81)$ & $0.06(1.52)$ \\
\hline & ECT $0.00(0.71)$ & & & \\
\hline \multirow[t]{2}{*}{ Lag order (Weeks) } & Dependent market & \multicolumn{3}{|c|}{ Independent markets } \\
\hline & $\Delta \mathrm{INBSE}$ & $\Delta \mathrm{BDSE}$ & $\Delta \mathrm{PKSE}$ & $\Delta$ SRLK \\
\hline \multirow[t]{2}{*}{1} & $0.07 *(2.45)$ & $-0.01(-0.67)$ & $0.00(0.63)$ & $-0.10(-0.34)$ \\
\hline & $\mathrm{ECT}-0.00(-1.23)$ & & & \\
\hline \multirow[t]{2}{*}{ Lag order (Weeks) } & Dependent market & \multicolumn{3}{|c|}{ Independent markets } \\
\hline & $\Delta \mathrm{PKSE}$ & $\Delta \mathrm{BDSE}$ & $\Delta \mathrm{INBSE}$ & $\Delta$ SRLK \\
\hline \multirow[t]{2}{*}{1} & $0.12 *(4.23)$ & $0.05(0.54)$ & $0.69 *(3.55)$ & $0.09(0.73)$ \\
\hline & ECT $-0.02(-1.71)$ & & & \\
\hline \multirow[t]{2}{*}{ Lag order (Weeks) } & Dependent market & \multicolumn{3}{|c|}{ Independent markets } \\
\hline & $\Delta$ SRLK & $\Delta \mathrm{BDSE}$ & $\Delta \mathrm{INBSE}$ & $\Delta \mathrm{PKSE}$ \\
\hline \multirow[t]{2}{*}{1} & $0.26 *(9.14)$ & $0.04(1.83)$ & $0.04(0.79)$ & $0.01(0.29)$ \\
\hline & ЕСТ $0.01 *(4.79)$ & & & \\
\hline
\end{tabular}

The error correction term (ECT) for the markets of Bangladesh, India, Pakistan and Sri Lanka is derived by normalising the cointegrating vector for that specific market. Figures in parenthesis are the t-statistics. Values with an *show significance at the five per cent level

markets; the ECT results indicate how quickly the previous period deviation from the long-run equilibrium is corrected. The value of -0.02 is an estimate of the adjustment parameter, and the value in parenthesis $(-1.71)$ is its t-statistic value. The short-run coefficient values reveal that, along with the market's own changes, Indian equities from previous weeks have an influence on the changes in share prices for the Pakistani market. Finally, the last panel of Table 4 indicates a significant long-run coefficient value for the ECT (0.01) with a $t$-statistic of 4.79. However, the short-run coefficients suggest that the Sri Lankan market is only influenced by lagged values of its own price changes.

Surprisingly, therefore, there is little evidence of spillover among returns from one market to another with the exception of India and Pakistan. This result suggests that the Indian market may be relatively independent in the system of the four markets over the long run. In addition, it shows the leadership role of the Indian market in the region-that is, in the long run, the Indian market is not led by the three relatively smaller markets of the region, but it can influence the Pakistani market.

Overall, the results of the VECM for the four South Asian markets indicate that the three stock markets of Bangladesh, Pakistan and Sri Lanka respond to disequilibrium in the price system in a fairly rapid fashion, the coefficient value on 
the significant $\mathrm{ECT}^{18}$ indicates a relatively fast speed of adjustment towards longrun equilibrium in the Sri Lankan market. In addition, stock price changes among these markets are predictable from their own lagged prices. Therefore, although the markets in the South Asian region violate the weak form of the EMH, they return to equilibrium in a rapid fashion. In addition, these results confirm the cointegration results in Table 3 about the existence of the long-run relationship among the markets.

\section{Return and volatility spillover analysis}

To address the research objectives of this paper, a tetra-variate GARCH-BEKK model, which is a MGARCH-BEKK model with four dependent variables, was selected due to its ability to examine volatility spillovers for more than two countries simultaneously and allow the presence of time-varying cross-market spillover to be examined. Based on the changes in return co-movement which emerge from Fig. 1 and the findings in Sect. 4, the effects of regional structural reform, as well as the post-crisis period on regional risk transmission, are investigated by estimating three tetra-variate GARCH-BEKK models for the three sub-periods mentioned in Sect. 3. Such effects are omitted in prior studies that have used other methods of analysis such as cointegration, univariate GARCH and diagonal MGARCH.

The separate estimation of three tetra-variate GARCH models for the three subperiods permits an examination of not only shifts in volatilities and covariances in the different time periods but also changes in the pattern of risk transmission through shock and volatility spillover from one market to the other three markets. By contrast, the inclusion of a dummy variable for "the period after the establishment of SAFE" or "the post-crisis period" in the mean and variance equations only facilitates an examination of shifts in the returns, volatilities and covariances of these four markets. ${ }^{19}$ The volatility of a market and its covariance with another market can affect the volatility and covariance of the third stock market, and this effect can vary with changes to the economic environment (Simmons and Tantisantiwong 2012). Therefore, we estimate three tetra-variate GARCH models for the three sub-periods instead of employing dummy variables. The differences between constant terms in the variance equations of these three models indicate shifts in volatilities and covariance, while the differences between coefficients for the same variable can indicate that risk spillovers among the four stock markets changed after the establishment of SAFE and after the world experienced an economic downturn.

\footnotetext{
18 The ECT shows the long-run relationship, while the short-run relationship is evident from the lagged stock price changes in the four markets. It shows that, in the short run, fluctuations in the Indian market explain movements in the Pakistani market. This result may be explained by the dominance of the market in terms of size and market capitalisation (see Table 1).

19 The inclusion of an interaction term between (i) the dummy variable and the lagged returns in the mean equation; and (ii) the dummy variable and lagged shocks and conditional variances in the variance equation will increase the number of coefficients and decrease the efficiency of estimation as well as the degrees of freedom.
} 
Apart from a spillover index proposed by Diebold and Yilmaz (2009), the multivariate GARCH model is employed in many research papers concerned with the study of volatility spillovers. For example, Erten et al. (2012) analyse the presence and magnitude of volatility transmissions among emerging markets using this approach. More recently, Liu (2016) tests for volatility effects in major equity markets, while Li and Giles (2015) investigate volatility spillovers between developed stock markets and Asian emerging stock markets using the multivariate GARCH model. Adopting a more regional approach, MacDonald et al. (2018) examine volatility co-movements and spillover effects within Eurozone economies. Throughout the literature, the GARCH-BEKK model is employed when investigating spillovers because of its ability to analyse return and volatility linkages as well as shocks (Kumar 2013). Therefore, the current study employs the GARCH-BEKK model to complement the existing body of literature by examining how the South Asian emerging markets are linked together in the region.

In particular, a tetra-variate GARCH model using the parameterisation of BEKK proposed by Engle and Kroner $(1995)^{20}$ is used. To analyse the risk spillover across the markets, mean and variance equations of the following form are used:

$$
\begin{gathered}
R_{t}=\mu+\Gamma R_{t-1}+\Sigma_{t} \quad \Sigma_{t} \mid I_{t-1} \sim N(0, H t) \\
H_{t}=C^{\prime} C+A^{\prime} \varepsilon_{t-1}^{\prime} \varepsilon_{t-1} A+G^{\prime} H_{t-1} G
\end{gathered}
$$

where

$$
\begin{gathered}
H_{t}=\left[\begin{array}{llll}
h_{11, t} & h_{12, t} & h_{13, t} & h_{14, t} \\
h_{21, t} & h_{22, t} & h_{23, t} & h_{24, t} \\
h_{31, t} & h_{32, t} & h_{33, t} & h_{34, t} \\
h_{41, t} & h_{42, t} & h_{43, t} & h_{44, t}
\end{array}\right] ; \quad A=\left[\begin{array}{llll}
a_{11} & a_{12} & a_{13} & a_{14} \\
a_{21} & a_{22} & a_{23} & a_{24} \\
a_{31} & a_{32} & a_{33} & a_{34} \\
a_{41} & a_{42} & a_{43} & a_{44}
\end{array}\right] ; \\
G=\left[\begin{array}{llll}
g_{11} & g_{12} & g_{13} & g_{14} \\
g_{21} & g_{22} & g_{23} & g_{24} \\
g_{31} & g_{32} & g_{33} & g_{34} \\
g_{41} & g_{42} & g_{43} & g_{44}
\end{array}\right] ; \quad C=\left[\begin{array}{llll}
c_{11} & 0 & 0 & 0 \\
c_{21} & c_{22} & 0 & 0 \\
c_{31} & c_{32} & c_{33} & 0 \\
c_{41} & c_{42} & c_{43} & c_{44}
\end{array}\right]
\end{gathered}
$$

where $R_{t}$ is a $4 \times 1$ vector of weekly returns at time $t\left(R_{i t}\right)$ with $i=1$ for the stock exchange indices of Bangladesh (BDSE), $i=2$ for India (INSE), $i=3$ for Pakistan (PKSE) and $i=4$ for Sri Lanka (SLSE). $\mu$ is a $4 \times 1$ vector of constant terms, and $\Gamma$ is a $4 \times 4$ matrix of parameters associated with the first lagged return values. The diagonal elements in matrix $\Gamma$ are $\gamma i i$ which measure the effects of own past returns on current price changes. The off-diagonal elements of the matrix $\Gamma$, $\gamma i j$, capture

\footnotetext{
${ }^{20}$ The model's formulation has two main problems. First, the number of parameters to be estimated is large and, second, restrictions are needed on the parameters to ensure that the conditional variance matrix is positive definite. To overcome these problems, Engle and Kroner (1995)'s BEKK model is employed.
} 
any return spillover effects across the markets. That is, previous returns in market $j$ may affect current returns in market $i$. $\Sigma_{t}$ is a $4 \times 1$ vector of random error terms, i.e. $\Sigma_{t}^{\prime}=\left[\begin{array}{llll}\varepsilon_{1, t} & \varepsilon_{2, t} & \varepsilon_{3, t} & \varepsilon_{4, t}\end{array}\right]$ where $\varepsilon_{i, t}$ is the innovation or shock for each market at time $t$. $I_{t-1}$ represents the market information available at time $t-1$. $\Sigma_{t}$ has zero means and conditional variances and covariances expressed in Eq. (6). The variance-covariance matrix $H_{t}$ is composed of $h_{i i, t}$ which describe the conditional variance for each of the four markets at time $t$ and $h_{i j, t}$ represents the conditional covariance. $\mathrm{C}$ is the matrix of constant terms, while $\mathrm{A}$ and $\mathrm{G}$ are matrices of coefficients. $C$ is a $4 \times 4$ lower triangular matrix with 10 parameters. $A$ is a $4 \times 4$ square matrix of parameters and shows how conditional variances are correlated with past squared errors. The elements of matrix $A$ measure the effects of shocks or 'news' on conditional variances. $G$ is also a $4 \times 4$ square matrix of parameters and shows how past conditional variances affect current levels of conditional variances.

The diagonal parameters in matrix A (matrix G)-that is, $a_{i i}\left(g_{i i}\right)$ measure the effects of own past shocks (past volatility of market $i$ ) on its conditional variance. The off-diagonal parameters in matrix $A$ (matrix $G$ )—-that is $a_{i j}\left(g_{i j}\right)$-measure the cross-market effects of shocks (covariances). Shocks that have happened in the past week in other markets or the lagged volatility or covariance of other markets can affect the volatility of a particular market or the market's co-movement with others; these are described by their respective coefficients $a_{i j}\left(g_{i j}\right)$. These effects are known as shock and volatility spillovers. The total number of estimated elements for the variance equations in the current analysis is 42 .

The tetra-variate GARCH-BEKK model in Eq. (6) can be estimated efficiently and consistently using the full information maximum likelihood method. In this paper, the model is estimated by using a quasi-maximum likelihood approach (QML) (Bollerslev and Wooldridge 1992). ${ }^{21}$ The Broyden, Fletcher, Goldfarb and Shanno (BFGS) algorithm is used to produce the maximum likelihood estimates of parameters and their corresponding asymptotic standard errors. ${ }^{22}$

Table 5 presents the estimates of elements in the coefficient matrices of the mean and variance equations for the three sub-periods. Significance of the coefficients therefore depends on significance of the relevant elements. Inter-relationships in terms of return, shock and volatility spillovers across the four markets are measured by $\gamma_{i j}$ the off-diagonal elements in Table 5. Note that the coefficients for the lagged return in the mean equation presented in the top panel of Table 5 are reported as the transpose of the matrix $\Gamma$. The estimates of matrices $A$ and $G$ are reported in the middle and bottom panels of Table 5 without transposing the elements. Shock and volatility spillovers from market $i$ to market $j$ (from market $j$ to market $i$ ) are measured by the element of $a_{i j}$ and $g_{i j}\left(a_{j i}\right.$ and $\left.g_{j i}\right)$. The significance of these elements

\footnotetext{
${ }_{21}$ The paper uses the quasi-maximum likelihood (QML) estimation approach following Bollerslev and Wooldridge (1992) who argue that QML estimations are relatively less biased while analysing GARCH models. Consequently, the results of this paper are robust to heteroscedasticity in the presence of GARCH effects.

22 The BFGS algorithm is used in several articles (Kanas, 1998; Hassan and Malik, 2007; Eissa et al., 2010). The Berndt, Hall, Hall and Hausman (BHHH) algorithm is also tested, but the BFGS is found to perform better in terms of model convergence.
} 


\begin{tabular}{|c|c|c|c|c|c|}
\hline & $\begin{array}{ll}\sqrt[W]{n} & + \\
& .1\end{array}$ & 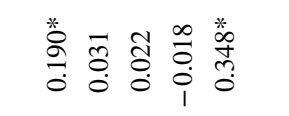 & 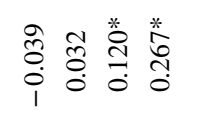 & 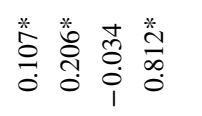 & 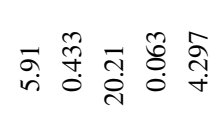 \\
\hline & & 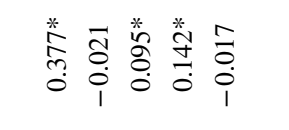 & 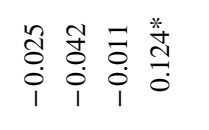 & 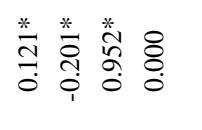 & m \\
\hline & & 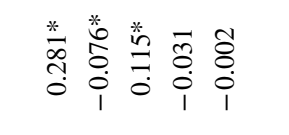 & 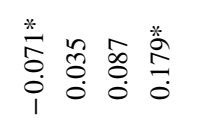 & 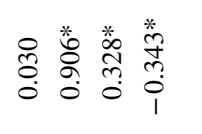 & 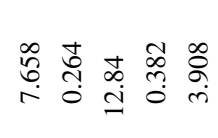 \\
\hline 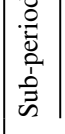 & & 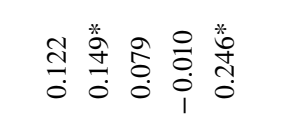 & 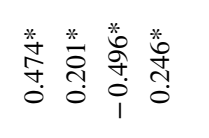 & 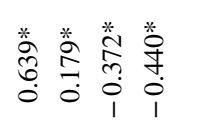 & 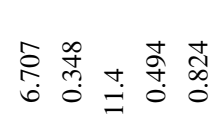 \\
\hline & 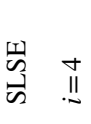 & 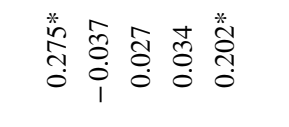 & 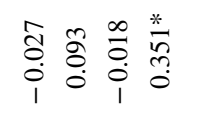 & 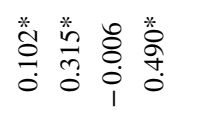 & 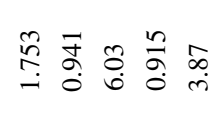 \\
\hline & $\begin{array}{ll}\sqrt[n]{2} & 0 \\
& 0\end{array}$ & 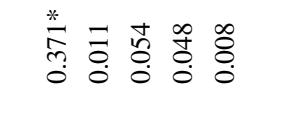 & 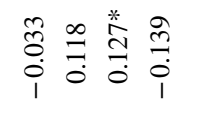 & 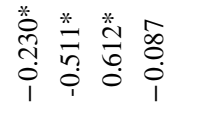 & 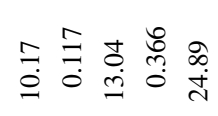 \\
\hline & & 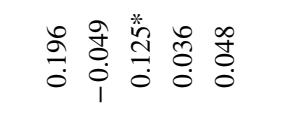 & 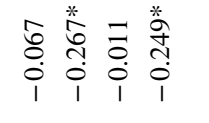 & 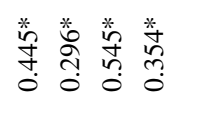 & 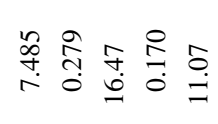 \\
\hline 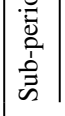 & & 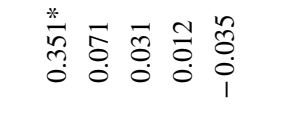 & 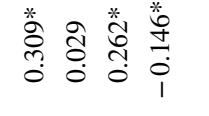 & 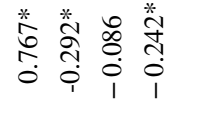 & 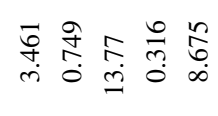 \\
\hline & 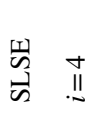 & 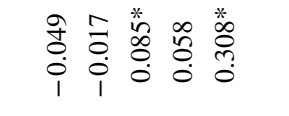 & 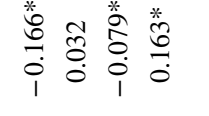 & 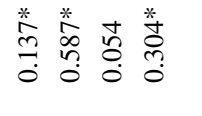 & $\underset{\dot{\mathrm{d}}}{\mathrm{g}} \overline{\mathrm{a}}$ \\
\hline & 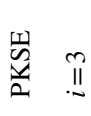 & 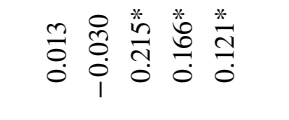 & 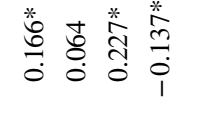 & 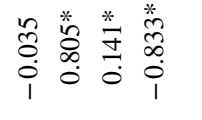 & 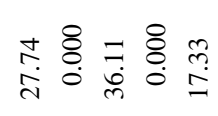 \\
\hline & $\begin{array}{lll}\text { 焉 } & \text { II } \\
\text { Z } & .\end{array}$ & 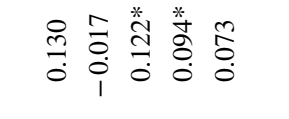 & 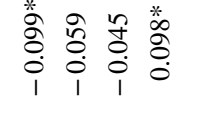 & 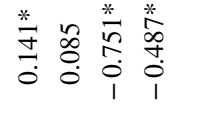 & 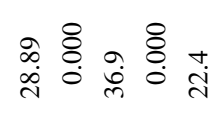 \\
\hline 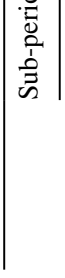 & 秥. & 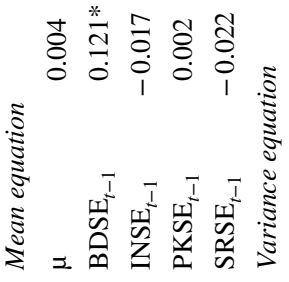 & 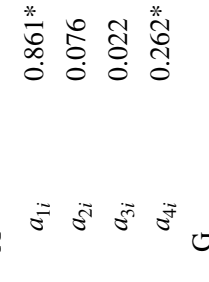 & 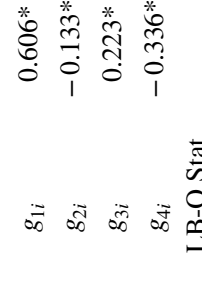 & 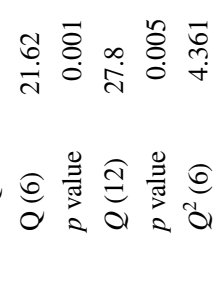 \\
\hline
\end{tabular}




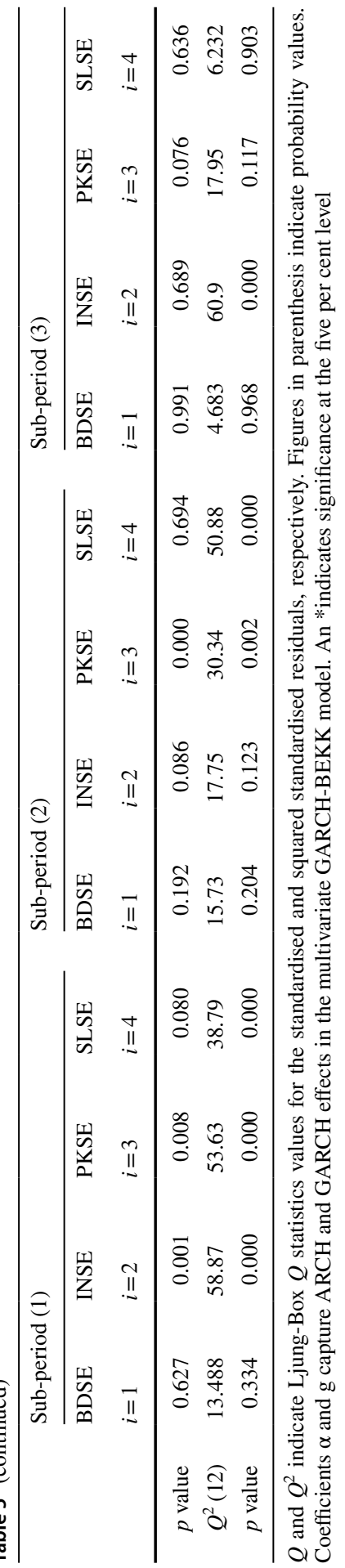


therefore indicates the existence of cross-market spillovers of shocks (volatility) among the markets.

\subsection{Before the establishment of SAFE (sub-period 1)}

Table 5 documents the results for spillovers in all three periods. For the first subperiod, the findings indicate bidirectional spillovers between PKSE and INSE index returns and unidirectional spillovers from the INSE index return to the SLSE index return $^{23}$ and from the SLSE index returns to PKSE and BDSE index returns. ${ }^{24}$ In particular, increases in PKSE and SLSE index returns are associated with increases in the INSE index returns in the previous week. This finding implies that the Bangladeshi stock market is linked with the Indian and Pakistani stock markets through the Sri Lankan stock market. India, being weakly exogenous to the regional stock markets studied, acts as the risk transmitter in the region, while Sri Lanka acts as the mediator of return spillover between Bangladesh and other markets in the region. It supports the finding from the PCA that Bangladesh is less connected with the other markets in South Asia during the first period.

In the first sub-period, the four South Asian markets are more connected with each other through shock and volatility spillovers. There are bidirectional shock spillovers between SLSE and PKSE and between SLSE and BDSE. Unidirectional shock spillovers from SLSE to INSE and from BDSE to PKSE as well as INSE are also discovered. The results also show that the past shocks of the Indian market do not affect any markets. Thus, while SLSE plays a role as the intermediary and BDSE as the recipient for return spillover, their roles change into a spreader for shock spillover. The role of INSE also changes from being a spreader for return spillover to becoming a shock recipient. It is notable that there is no direct shock spillovers between INSE and PKSE, but their bidirectional spillovers are uncovered for volatility spillover. There are also two unidirectional spillovers: one is from SLSE to PKSE and another is from PKSE to BDSE. Thus, BDSE market volatility can be affected by a change in the volatility of SLSE and INSE both directly and indirectly through volatility spillover from PKSE.

\footnotetext{
23 This result is in agreement with the findings of Gunasinghe (2005) who employs a cointegration test and impulse response functions and discovers that shocks originating in the Indian market spill over to the markets of Pakistan and Sri Lanka and hence these markets are vulnerable to spillover effects that originate in the Indian stock market.

24 The findings call the efficiency of these markets into question. According to Harris and Pisedtasalasai (2006, p.1556), "In an efficient market, and in the absence of time-varying risk premia, it should not be possible to forecast the returns of one stock using the lagged returns of another stock. The findings that there are spillover effects in returns implies the existence of an exploitable trading strategy and, if trading strategy profits exceeds transaction costs, potentially represents evidence against market efficiency".
} 


\subsection{The global economic boom pre-crisis (sub-period 2)}

Unlike the results for the first sub-period, the findings for the second sub-period show that all constant terms in the mean equation are significantly positive. This result implies that the mean values of stock returns in all four markets increased significantly after the establishment of SAFE, reflecting a benefit of this regional cooperation and market reforms. It is notable that there are no longer return spillovers among the four stock markets.

Fewer pairs of shock and volatility spillovers are also present in the second period. There are bidirectional shock spillovers between SLSE and two markets: BDSE and INSE. In addition, a unidirectional shock spillover exists from PKSE to BDSE; this result is the opposite of what happened in the first sub-period. That is, the PKSE becomes weakly exogenous in this period; a shock from PKSE is transmitted to other markets in the region through BDSE's responses to the shock in PKSE. This implies that the PKSE became a more influential market in the region after the setup of SAFE. Such a change may have been due to the large inflow of funds from the USA to Pakistan during the war-on-terror period after 9/11. According to Suleman (2012), Pakistan gained a total of US\$11.998 billion in international support during the 10-year period from 2001 to 2010. During the second sub-period, volatility spillover is more prominent than shock spillover. The bidirectional volatility spillovers in this period are the same as those in the first period in terms of pairings, but different in terms of size. The size of bidirectional volatility spillover effects between BDSE and INSE become larger after the setup of SAFE, while the size of the spillover effects between SLSE and INSE and between PKSE and INSE becomes smaller. In addition, the unidirectional volatility spillover from SLSE to PKSE no longer exists. Moreover, the direction of volatility spillover between PKSE and BDSE in this period is the opposite to that uncovered in the first sub-period.

Thus, the results suggest that there is no direct relationship between the PKSE and the SLSE. The role of the BDSE as a recipient of return and volatility transmission and a spreader for shock transmission in the first sub-period changes to be an intermediary for all transmissions in the second sub-period. Meanwhile, the PKSE, which used to be the intermediary of volatility transmission in the first period, becomes the risk spreader for shock spillover and the risk recipient for the volatility spillover in the second period. The role of the INSE in the regional risk transmission is dissipated in this period.

\subsection{The post-crisis period}

In this period, the return and risk transmissions are more evident than in the previous two sub-periods. The results suggest that there are one-way return spillovers from SLSE to BDSE, from BDSE to INSE and from INSE to PKSE. This finding clearly indicates that SLSE is the transmitter and the PKSE is the recipient, with BDSE and INSE being the intermediaries in the transmission process.

Shock spillovers in this last sub-period become more prominent during the global economic recession. The pattern of shock spillovers in this period is quite similar 
to the first sub-period. For example, there is no direct transmission between INSE and PKSE and a unidirectional spillover is found from SLSE to INSE. In addition, the bidirectional transmission between SLSE and PKSE reappears after its disappearance during the second sub-period. However, there are few differences between shock spillovers in the first and last sub-periods for pairings involving BDSE. That is, the bidirectional relationship between SLSE and BDSE changes to a unidirectional transmission from SLSE to BDSE while the unidirectional spillover from BDSE to INSE changes into a bidirectional transmission between the two markets. Meanwhile, the direction of the spillover between PKSE and BDSE is reversed. As a result, the role of BDSE changes from being a risk spreader in the first sub-period and an intermediary in the second sub-period to being a risk recipient in the last sub-period.

Patterns among the volatility spillovers of the three sub-periods are generally similar. Yet, a number of differences exist. First, a bidirectional relationship between INSE and BDSE in the first two sub-periods changes into a unidirectional spillover from the larger market (INSE) to the smaller market (BDSE) in the third sub-period. Second, a unidirectional transmission between BDSE and PKSE in the first and second sub-periods becomes a bidirectional transmission in the third sub-period. In this third sub-period, there is still no direct relationship between SLSE and PKSE. These results indicate that, for volatility spillover, the position of risk spreader changes from the SLSE in the first period to the BDSE in the second period and to the INSE in the third period. ${ }^{25}$

To sum up, the results indicate that there is less evidence of spillover transmissions among the region's markets after the establishment of SAFE, but the markets benefit from the higher average stock returns and the improvement in market efficiency. There is no return spillover and less shock and volatility spillovers in the second sub-period; further, only Indian and Sri Lankan market returns can be predicted by past returns in the second sub-period, while all markets are weak form inefficient in the first sub-period. Comparing the last two sub-periods, it is apparent that the return and shock transmissions become stronger during the global economic recession, suggesting some contagion within the region. These results are in agreement with most previous studies that find higher volatility spillovers after a crisis period (Wang et al. 2005; Nikkinen et al. 2008) and document greater linkages among emerging markets after crisis events (Yang et al. 2003; Click and Plummer 2005; Meric et al. 2008). Another major finding is that the patterns of return, shock and volatility transmissions are different and they change from period to period. In particular, the role of each market in the transmission varies with the period analysed. Moreover, the role of the Indian market becomes more prominent in the last

\footnotetext{
25 According to Hakkio and Rush (1991), the length of time is more important for analysing the longterm inter-relationship among financial markets than the frequency of data. In order to avoid any noise in the data during the global financial crisis period, 24 observations are excluded from the cointegration and multivariate GARCH analysis to focus on whether any relationship is present among the markets during normal periods rather than when unusual turbulent events are occurring. In addition, for both these modelling approaches, a longer time period is required for analysis and these observations are too few for analysing a crisis period on its own.
} 
sub-period. The increasing role of the Indian market in return and risk spillovers in the last period compared to the second period may also be due to the relatively greater development of the Indian financial market.

\section{Conclusion}

This paper investigates return and volatility spillover effects between the four emerging stock markets of Bangladesh, India, Pakistan and Sri Lanka. Evidence of linkages in terms of both return and volatility are found after employing a cointegration test and the MGARCH-BEKK model to weekly stock market returns.

The result from the cointegration test indicates that there is a long-run relationship between these four markets over the period 1993-2015. The estimates of MGARCH-BEKK model for three different periods highlight the change in the pattern of return and risk transmissions among the region's markets. After the establishment of SAFE, the markets benefit from the higher average stock returns and the improvement in market efficiency with less risk spillovers. However, with the integration of trading systems among the SAFE's member countries, each market has greater exposure to external shocks from the other markets within the region.

It is evident that the importance of return spillovers becomes more pronounced for India after the establishment of SAFE and the global economic boom. The role of BDSE in shock spillovers changes from being a risk spreader in the first subperiod and an intermediary in the second sub-period to being a risk recipient in the last sub-period. For volatility spillover, the position of risk spreader changes from the SLSE in the first period to the BDSE in the second period and to the INSE in the third period.

International portfolio diversification has grown in popularity over the recent past, and foreign investors invest in various emerging stock markets around the globe in order to reduce risk. This paper uncovers evidence of transmission among South Asian stock markets and shows that stock markets in this region interact with each other in terms of return and volatility. In particular, share price changes can be predicted from historical share price movements in the region; hence, the markets in the region violate the weak form of the EMH. In addition, information transmits from the relatively larger markets of India and Pakistan and spreads to the smaller markets mainly via volatility rather than return spillovers, especially in the period after the establishment of SAFE no matter whether the global market faces an economic boom or crisis. The findings have implications for potential foreign investors investing in the region in terms of benefits from diversification; the impact of 'news' on one stock market can spread to other markets in the region through their interdependence.

Acknowledgements The authors wish to thank two anonymous referees for their constructive comments and advice on an earlier draft of this paper.

Open Access This article is licensed under a Creative Commons Attribution 4.0 International License, which permits use, sharing, adaptation, distribution and reproduction in any medium or format, as long as you give appropriate credit to the original author(s) and the source, provide a link to the Creative 
Commons licence, and indicate if changes were made. The images or other third party material in this article are included in the article's Creative Commons licence, unless indicated otherwise in a credit line to the material. If material is not included in the article's Creative Commons licence and your intended use is not permitted by statutory regulation or exceeds the permitted use, you will need to obtain permission directly from the copyright holder. To view a copy of this licence, visit http://creativecommons.org/ licenses/by/4.0/.

\section{References}

Alomari, M., Power, D.M., Tantisantiwong, N.: Determinants of equity return correlations: a case study of the amman stock exchange. Rev. Quant. Financ. Acc. 50(1), 33-66 (2018)

Arshanapalli, B., Doukas, J.: International stock market linkages: evidence from the pre- and post- October 1987 period. J. Bank. Finance 17, 193-208 (1993)

Banik, N., Biswas, B., Criddle, K.R.: Optimum currency area in South Asia: a state space approach. Int. Rev. Econ. Finance 18, 502-510 (2009)

Baumöhl, E., Kočenda, E., Lyócsa, S., Výrost, T.: Networks of volatility spillovers among stock markets. Phys. A Stat. Mech. Its Appl. 490, 1555-1574 (2018)

Bekaert, G., Harvey, C.R.: Time-varying world market integration. J. Finance 50, 403-444 (1995)

Bekaert, G., Harvey, C.R., Lundblad, C.T.: Equity market liberalisation in emerging markets. J. Financ. Res. 26, 275-299 (2003)

BenSaïda, A., Litimi, H., Abdallah, O.: Volatility spillover shifts in global financial markets. Econ. Modell. 73, 343-353 (2018)

Bollerslev, T., Wooldridge, J.M.: Quasi-maximum likelihood estimation and inference in dynamic models with time-varying covariances. Economet. Rev. 11, 143-172 (1992)

Brooks, C.: Introductory econometrics for finance, 3rd edn. Cambridge University Press, Cambridge, UK (2014)

Caloia, F.G., Cipollini, A., Muzzioli, S.: Asymmetric semi-volatility spillover effects in EMU stock markets. Int. Rev. Financ. Anal. 57, 221-230 (2018)

Charles, A., Darne, O.: Large shocks and the September 11th terrorist attacks on international stock markets. Econ. Modell. 23, 683-698 (2006)

Chen, G.M., Firth, M., Rui, O.M.: Stock market linkages: evidence from Latin America. J. Bank. Finance 26, 1113-1141 (2002)

Chevallier, J., Nguyen, D.K., Siverskog, J., Uddin, G.S.: Market integration and financial linkages among stock markets in Pacific Basin countries. J. Emp. Finance 46, 77-92 (2018)

Chou, R.Y., Lin, J.L., Wu, C.S.: Modelling the Taiwan stock market and international linkages. Pac. Econ. Rev. 4(3), 305-320 (1999)

Chow, H.K.: Volatility spillovers and linkages in Asian stock markets. Emerg. Mark. Finance Trade 53, 2770-2781 (2017)

Chuang, I.-Y., Lu, J.R., Tswei, K.: Interdependence of international equity variances: evidence from East Asian markets. Emerg. Mark. Rev. 8, 311-327 (2007)

Click, R.W., Plummer, M.G.: Stock market integration in ASEAN after the Asian financial crises. J. Asian Econ. 16, 5-28 (2005)

Conrad, C., Karanasos, M., Zeng, N.: Multivariate fractionally integrated APARCH modeling of stock market volatility: a multi-country study. J. Emp. Finance 18, 147-159 (2011)

Davidson, S. N.: Interdependence or contagion: a model switching approach with a focus on Latin America. Econ. Modell. In Press (2019)

Dedi, L., Yavas, B.F.: Return and volatility spillovers in equity markets: an investigation using various GARCH methodologies. Cogent Econ. Finance 4(1), 1-18 (2016)

Diebold, F.X., Yilmaz, K.: Measuring financial asset return and volatility spillovers, with application to global equity markets. Econ. J. 119(534), 158-171 (2009)

Diamandis, P.F.: International stock market linkages: evidence from Latin America. Glob. Finance J. 20, 13-30 (2009)

Eissa, M.A., Chortareas, G., Cipollini, A.: Stock returns and exchange rate volatility spillovers in the MENA region. J. Emerg. Mark. Finance 9(3), 257-284 (2010) 
Engle, R.F., Granger, C.W.J.: Co-integration and error correction: representation, estimation and testing. Econometrica 55, 251-276 (1987)

Engle, R.F., Kroner, K.F.: Multivariate simultaneous generalized ARCH. Econ. Theory 11, 122-150 (1995)

Erten, I., Tuncel, M.B., Okay, N.: Volatility spillovers in emerging markets during the global financial crisis: Diagonal BEKK approach. MPRA Paper No. 56190 (2012). https://mpra.ub.unimuenchen. de/56190. Accessed 19 Mar 2021

Gilmore, C.G., McManus, G.M.: International portfolio diversification: US and Central European equity markets. Emerg. Mark. Rev. 3, 69-83 (2002)

Goldberg, C.S., Delgado, F.A.: Financial integration of emerging markets: an analysis of Latin America versus South Asia using individual stocks. Multinatl. Finance J. 5(4), 259-301 (2001)

Gunasinghe, W.: Behaviour of stock markets in South Asia: an econometric investigation. South Asia Econ. J. 6, 165-191 (2005)

Hamao, Y., Masulis, R., Ng, V.: Correlations in price changes and volatility across international stock markets. Rev. Financ. Stud. 3, 281-307 (1990)

Hameed, A., Ashraf, H.: Stock market volatility and weak form efficiency: evidence from an emerging market. Int. J. Bus. Emerg. Mark. 1(3), 249-263 (2006)

Harris, R.D.F., Pisedtasalasai, A.: Return and volatility spillovers between large and small stocks in the UK. J. Bus. Finance Acc. 33, 1-16 (2006)

Hassan, S.A., Malik, F.: Multivariate GARCH modelling of sector volatility transmission. Q. Rev. Econ. Finance 47, 470-480 (2007)

Henry, P.B.: Stock market liberalization, economic reform, and emerging market equity prices. J. Finance 55, 529-564 (2000)

Hung, N.T.: Return and volatility spillover across equity markets between China and Southeast Asian countries. J. Econ. Finance Admin. Sci. 24, 66-81 (2019)

Iqbal, M.J., Rafique, S., Abrar, A., Jamil, N., Shah, A.A., Satti, A.H.: Volatility linkages between equity markets of Pakistan, India, Singapore and Hong Kong: a GARCH BEKK approach. J. Econ. Behav. Stud. 4(1), 47-54 (2012)

Jain, P., Sehgal, S.: An examination of return and volatility spillovers between mature equity markets. J. Econ. Finance 43, 180-210 (2019)

Jayasuriya, S.: Stock market liberalisation and volatility in the presence of favourable market characteristics and institutions. Emerg. Mark. Rev. 6, 170-191 (2005)

Johansen, S.: Statistical analysis of cointegration vectors. J. Econ. Dyn. Control 12, 231-254 (1988)

Johansen, S.: Estimation and hypothesis testing of cointegration vectors in gaussian vector autoregressive models. Econometrica 59(6), 1551-1580 (1991)

Johansen, S., Juselius, K.: Maximum likelihood estimation and inference on cointegration-with applications to the demand for money. Oxford Bull. Econ. Stat. 52(2), 169-210 (1990)

Joshi, P.: Return and volatility spillovers among Asian stock markets. Sage Open 1, 1-8 (2011)

Kanas, A.: Volatility spillovers across equity markets: European evidence. Appl. Financ. Econ. 8, 245256 (1998)

Karolyi, G.A., Stulz, R.M.: Why do markets move together? An investigation of US-Japan stock return comovements using ADRs. J. Finance 51, 951-986 (1996)

Kassimatis, K.: Financial liberalisation and stock market volatility in selected developing countries. Appl. Financ. Econ. 12, 389-394 (2002)

Khalid, A.M., Rajaguru, G.: Financial market linkages in South Asia: evidence using a multivariate GARCH model. Pak. Dev. Rev. 43(4), 585-603 (2004)

Kim, E.H., Singal, V.: Stock market openings: experience of emerging economies. J. Bus. 73, 25-66 (2000)

King, M., Wadhwani, S.: Transmission of volatility between stock markets. Rev. Financ. Stud. 3, 5-33 (1990)

Koutmos, G., Booth, G.G.: Asymmetric volatility transmission in international stock markets. J. Int. Money Finance 14, 747-762 (1995)

Kumar, M.: Returns and volatility spillovers between stock prices and exchange rates: Evidence from IBSA countries. Int. J. Emerg. Mark. 8(2), 108-128 (2013)

Lamba, A.S.: An analysis of the short- and long-run relationships between South Asian and developed equity markets. Int. J. Bus. 10, 383-402 (2005)

Li, H.: International linkages of the Chinese stock exchanges: a multivariate GARCH analysis. Appl. Financ. Econ. 17, 285-295 (2007) 
Li, Y., Giles, D.: Modelling volatility spillover effects between developed stock markets and Asian emerging stock markets. Int. J. Finance Econ. 20, 155-177 (2015)

Li, H., Majerowska, E.: Testing stock market linkages for Poland and Hungary: a multivariate GARCH approach. Res. Int. Bus. Finance 22, 247-266 (2008)

Liu, C.: Spillover effects in major equity markets: A GARCH BEKK approach. Open Access Libr. J. 3(2), 1-21 (2016)

Liu, Y.A., Pan, M.S.: Mean and volatility spillover effects in the US and Pacific-Basin stock markets. Multinatl. Finance J. 1, 47-62 (1997)

Lu, W., Gao, Y., Huang, X.: Volatility spillovers of stock markets between China and Countries along the belt and road. Emerg. Mark. Finance Trade, In press (2019)

MacDonald, R., Sogiakas, V., Tsopanakis, A.: Volatility co-movements and spillover effects within the Eurozone economies: a multivariate GARCH approach using the financial stress index. J. Int. Financ. Mark. Inst. Money 52, 17-36 (2018)

MacKinnon, J.G., Haug, A.A., Michelis, L.: Numerical distribution functions of likelihood ratio tests for cointegration. J. Appl. Econ. 14(5), 563-577 (1999)

Majumder, S.B., Nag, R.N.: Shock and volatility spillovers among equity sectors of the national stock exchange in India. Glob. Bus. Rev. 19, 227-240 (2018)

Malik, F., Hammoudeh, S.: Shock and volatility transmission in the oil, US and Gulf equity markets. Int. Rev. Econ. Finance 16, 357-368 (2007)

Masih, R., Masih, A.M.M.: Common stochastic trends and the dynamic linkages driving European stock markets: evidence from pre- and post- October 1987 crash eras. Eur. J. Finance 10, 81-104 (2004)

Meric, I., Kim, S., Kim, J.H., Meric, G.: Co-movements of U.S., U.K., and Asian stock markets before and after September 11, 2001. J. Money Invest. Bank. 3, 47-57 (2008)

Narayan, P., Smyth, R., Nandha, M.: Interdependence and dynamic linkages between the emerging stock markets of South Asia. Acc. Finance 44, 419-439 (2004)

Newaz, M.K., Park, J.S.: The impact of trade intensity and market characteristics on asymmetric volatility, spillovers and asymmetric spillovers: evidence from the response of international stock markets to US shocks. Q. Rev. Econ. Finance 71, 79-94 (2019)

Nikkinen, J., Omran, M.M., Sahlstrom, P., Aijo, J.: Stock return and volatility following the September 11 attacks: evidence from 53 equity markets. Int. Rev. Financ. Anal. 17, 27-46 (2008)

Osterwald-Lenum, M.: A note with quantiles of the asymptotic distribution of the maximum likelihood cointegration rank tests. Oxf. Bull. Econ. Stat. 54(3), 461-472 (1992)

Panda, A. K., Nanda, S., Paital, R. R.: An empirical analysis of stock market interdependence and volatility spillover in the stock markets of Africa and Middle East region. Afr. J. Econ. Manag. Stud., In press (2016)

Roca, E.: Short-term and long-term price linkages between the equity markets of Australia and its major trading partners. Appl. Financ. Econ. 9(5), 501-511 (1999)

Scheicher, M.: The comovements of stock markets in Hungary, Poland and the Czech Republic. Int. J. Finance Econ. 6, 27-39 (2001)

Simmons, P., Tantisantiwong, N.: Equilibrium moment restrictions on asset returns: normal and crisis periods. Eur. J. Finance 20, 1064-1089 (2012)

Singh, A.: Financial liberalisation, stock markets and economic development. Econ. J. 107, 771-782 (1997)

Singh, P., Kumar, B., Pandey, A.: Price and volatility spillovers across North American, European and Asian stock markets. Int. Rev. Financ. Anal. 19, 55-64 (2010)

South Asian Federation of Exchanges. 2010. South Asian Financial Market Review

Standards and Poor's. 2009. Global Stock Markets Factbook

Standards and Poor's. 2010. Global Stock Markets Factbook

Suleman, M.T.: Stock market reaction to terrorist attacks: empirical evidence from a front line state. Aust. Acc. Bus. Finance J. 6, 97-110 (2012)

Syriopoulos, T.: International portfolio diversification to Central European stock markets. Appl. Financ. Econ. 14, 1253-1268 (2004)

Tay, N.S.P., Zhu, Z.: Correlations in returns and volatilities in Pacific-Rim stock markets. Open Econ. Rev. 11, 27-47 (2000)

Theodossiou, P., Lee, U.: Mean and volatility spillovers across major national stock markets: further empirical evidence. J. Financ. Res. 16, 337-350 (1993)

Virk, N., Javed, F.: European equity market integration and joint relationship of conditional volatility and correlations. J. Int. Money Finance 71, 53-77 (2017) 
Vo, X.V., Ellis, C.: International financial integration: stock return linkages and volatility transmission between Vietnam and advanced countries. Emerg. Mark. Rev. 36, 19-27 (2018)

Wang, Y., Gunasekarage, A., Power, D.M.: Return and volatility spillovers from developed to emerging capital markets: the case of South Asia. Contemp. Stud. Econ. Financ. Anal. 86, 139-166 (2005)

Weber, E., Zhang, Y.: Common influences, spillover and integration in Chinese stock markets. J. Emp. Finance 19, 382-394 (2012)

Worthington, A., Higgs, H.: Transmission of equity returns and volatility in Asian developed and emerging markets: a multivariate GARCH analysis. Int. J. Finance Econ. 9, 71-80 (2004)

Yang, J., Kolari, J.W., Min, I.: Stock market integration and financial crisis: the case of Asia. Appl. Financ. Econ. 13(7), 477-486 (2003)

Muhammad Niaz Khan is Assistant Professor in Finance at the University of Science and Technology Bannu, Pakistan. He graduated MBA Finance from the Institute of Business and Management Sciences, Agricultural University Peshawar, Pakistan. He was awarded a Diploma in Research and a PhD from the University of Dundee, Scotland, UK. His research interests include emerging capital markets, stock market integration and market efficiency.

Suzanne G. M. Fifield is a Senior Lecturer in Finance at the University of Dundee. After graduating Bachelor of Accountancy with First Class Honours from the University of Dundee, she achieved a Masters degree in Accounting and Finance from the London School of Economics and Political Science, and then a $\mathrm{PhD}$ in Finance from the University of Dundee. Her research interests include emerging financial markets, portfolio diversification, stock market efficiency and international accounting in emerging economies. She has published in a number of journals including Accounting Forum, the European Journal of Finance and the International Journal of Finance and Economics.

Nongnuch Tantisantiwong is a senior vice president at Krungthai Bank (Thailand), holding a visiting academic position at the School of Electronics and Computer Science at the University of Southampton (UK). She was awarded Bachelor and Master degrees in Economics from Chulalongkorn University (Thailand) and an MSc in Econometrics and Economics as well as a PhD in Economics from the University of York (UK). Her research interests include financial economics, derivatives and asset pricing, investment funds, banking, microfinance and fintech. She has published in journals including the Journal of Business Ethics, the British Accounting Review and the European Journal of Finance.

David M. Power is a Professor of Business Finance at the University of Dundee. He graduated MSc Econ from the London School of Economics and was awarded his PhD from the University of Dundee. His research interests include capital markets, financial communication by firms to investors and market efficiency. He has published widely in many journals including the British Accounting Review, Accounting Forum, Review of Quantitative Finance and Accounting and Quantitative Research in Economics and Finance. In 2020, he was given a Lifetime Achievement Award by the British Accounting \& Finance Association. 